\title{
Novel haloarchaeal viruses from Lake Retba infecting Haloferax and Halorubrum species
}

\section{Mizuno, Carolina M.}

2019-06

Mizuno , C M , Prajapati , B , Lucas-Staat , S , Sime-Ngando , T, Forterre , P , Bamford , D H , Prangishvili , D , Krupovic , M \& Oksanen , H M 2019 , ' Novel haloarchaeal viruses from Lake Retba infecting Haloferax and Halorubrum species ', Environmental Microbiology , vol. 21 , no. 6 , pp. 2129-2147 . https://doi.org/10.1111/1462-2920.14604

http://hdl.handle.net/10138/313687

https://doi.org/10.1111/1462-2920.14604

unspecified

acceptedVersion

Downloaded from Helda, University of Helsinki institutional repository.

This is an electronic reprint of the original article.

This reprint may differ from the original in pagination and typographic detail.

Please cite the original version. 


\section{Novel haloarchaeal viruses from Lake Retba infecting Haloferax and}

\section{Halorubrum species}

Carolina M. Mizuno ${ }^{1}$, Bina Prajapati ${ }^{2 \#}$, Soizick Lucas-Staat ${ }^{1}$, Telesphore Sime-Ngando ${ }^{3}$, Patrick Forterre ${ }^{1}$, Dennis H. Bamford ${ }^{2}$, David Prangishvili ${ }^{1}$, Mart Krupovic ${ }^{1 *}$, and Hanna M. Oksanen ${ }^{2 *}$

Unité Biologie Moléculaire du Gène chez les Extrêmophiles, Institut Pasteur, 25 rue du Docteur Roux, 75015 Paris , France

Molecular and Integrative Biosciences Research Programme, Faculty of Biological and Environmental Sciences, University of Helsinki, Finland

CNRS UMR 6023, Université Clermont-Auvergne, Laboratoire "Microorganismes: Génome et Environnement" (LMGE), F-63000 Clermont-Ferrand, France

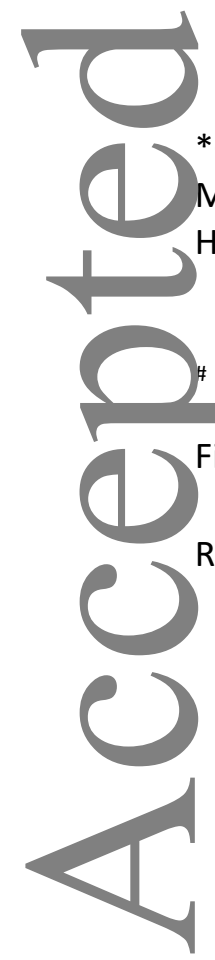

${ }^{\ddagger}$ Current affiliation: Cell and Molecular Biology Program, Institute of Biotechnology, University of Helsinki, Finland

Running title: Haloarchaeal Viruses of Lake Retba

This article has been accepted for publication and undergone full peer review but has not been through the copyediting, typesetting, pagination and proofreading process which may lead to differences between this version and the Version of Record. Please cite this article as doi: $10.1111 / 1462-2920.14604$ 


\section{Summary}

The diversity of archaeal viruses is severely undersampled compared to that of viruses infecting bacteria and eukaryotes, limiting our understanding on their evolution and environmental impacts. Here we describe the isolation and characterization of four new viruses infecting halophilic archaea from the saline Lake Retba, located close to Dakar on the coast of Senegal. Three of the viruses, HRPV10, HRPV11 and HRPV12, have enveloped pleomorphic virions and should belong to the family Pleolipoviridae, whereas the forth virus, HFTV1, has an icosahedral capsid and a long non-contractile tail, typical of bacterial and archaeal members of the order Caudovirales. Comparative genomic and phylogenomic analyses place HRPV10, HRPV11 and HRPV12 into the genus Betapleolipovirus, whereas HFTV1 appears to be most closely related to the unclassified Halorubrum virus HRTV-4. Differently from HRTV-4, HFTV1 encodes host-derived minichromosome maintenance helicase and PCNA homologs, which are likely to orchestrate its genome replication. HFTV1, the first archaeal virus isolated on a Haloferax strain, could also infect Halorubrum sp., albeit with an eight-fold lower efficiency, whereas pleolipoviruses nearly exclusively infected autochthonous Halorubrum strains. Mapping of the metagenomic sequences from this environment to the genomes of isolated haloarchaeal viruses showed that these known viruses are underrepresented in the

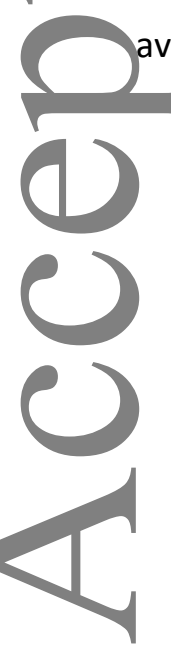




\section{Introduction}

Hypersaline environments, where salt concentration is close to saturating, harbor a high number of viruslike particles (VLP) but rather low microbial diversity (Oren, 2002; Pagaling et al., 2007; Sime-Ngando et al., 2011; Ventosa et al., 2015; Roux et al., 2016). Although these environments are dominated by archaea and bacteria, some eukaryotes are present, e.g. the salt-adapted unicellular green alga Dunaliella salina, some fungi and yeast, protozoa, and the brine shrimp Artemia (Triantaphyllidis et al., 1998; Gunde-Cimerman et al., 2018). Haloarchaeal virus predation is among the most important factors driving the genetic variation of different haloarchaeal species. For instance, most of the differences between the closely related species are mapped to the genes encoding for cell surface structures and their modification, which directly affect virus-host interactions (Cuadros-Orellana et al., 2007; Dyall-Smith et al., 2011; Tschitschko et al., 2018). As of today, more than 100 viruses have been isolated from hypersaline environments of which the majority infect extremely halophilic euryarchaea, all belonging to the class Halobacteria (Tang et al., 2004; Pagaling 1 et al., 2007; Atanasova et al., 2015b; Dyall-Smith et al., 2019). Halophilic viruses are well adapted to high

Salinity and some of them remain infectious even in saturated salt (Demina et al., 2016a). Some viruses can Jeven survive in low salinities, a beneficial trait under changing environmental conditions (Pietilä et al., 2013c). Halophilic archaeal viruses fall into four different morphological groups: spindle-shaped (genus Salterprovirus), pleomorphic (family Pleolipoviridae), tailless icosahedral (family Spherolipoviridae), and tailed icosahedral (order Caudovirales) (Pietilä et al., 2014; Pietilä et al., 2016; Demina et al., 2017). However, filamentous and some exceptional morphotypes not reminiscent of any isolated virus, e.g. hairpin-shaped, bacilliform, and chain-like VLPs, have also been visualized in hypersaline water bodies (Oren et al., 1997; Sime-Ngando et al., 2011; Di Meglio et al., 2016). Significant number of archaeal virus genes have no obvious homologs in public sequence databases (Krupovic et al., 2018). Thus, classification of viral sequences in metagenomic datasets is still a challenge due to the high genetic diversity, despite of remarkable advances in next-generation sequencing and bioinformatics. In addition, the relatively low number of described halophilic archaeal virus isolates with determined complete genome sequences limits the utility of sequence similarity-based analyses. For example, only few similarities to the NCBI non- 
redundant database at either the nucleotide or amino acid level were reported following the analyses of the metaviromes from hypersaline Lake Retba (Sime-Ngando et al., 2011; Roux et al., 2016) and halite endoliths in the Atacama Desert (Crits-Christoph et al., 2016).

Two groups of haloarchaeal viruses have been frequently isolated from geographically remote locations. These include members of the family Pleolipoviridae and the order Caudovirales, respectively. Membranecontaining virions of pleolipoviruses resemble extracellular membrane vesicles able to carry the virus genome from host to host (Pietilä et al., 2012). They represent a unique archaeal virus group with a recently established taxonomic position as the first family containing viruses with either single-stranded (ss) or double-stranded (ds) DNA genomes (linear or circular forms) (Pietilä et al., 2016; Bamford et al., 2017). The non-lytic pleomorphic virus life-cycle starts with fusion between the viral and host membranes and they exit the host cell most probably by budding, preserving the host membrane integrity (Svirskaite et al., 2016; El Omari et al., 2019). Their simplistic mechanism of nucleic acid transmission resembles the function of the recently described "infectious" plasmid membrane vesicles isolated from Antarctic species of haloarchaea (Erdmann et al., 2017), supporting the tight evolutionary relationships between viruses and non-viral mobile genetic elements (Iranzo et al., 2016b). Pleolipoviruses share a conserved core of four to five genes, mainly encoding major structural proteins of which one is the spike protein responsible for host attachment and membrane fusion (Pietilä et al., 2012; Sencilo et al., 2012; El Omari et al., 2019).

.

The tailed icosahedral dsDNA viruses represent the most numerous archaeal virus group described today (Atanasova et al., 2015a). Intriguingly, all these viruses infect halophiles or methanogens of the phylum Euryarchaeota (Prangishvili et al., 2017). However, the identified proviruses and metagenomic studies suggest wider association of archaeal tailed viruses across different orders within the Euryarchaeota, but also with members of the phylum Thaumarchaeota (Krupovic et al., 2010a; Krupovic et al., 2011b; Danovaro et al., 2016; Philosof et al., 2017; Vik et al., 2017; Abby et al., 2018; Ahlgren et al., 2019; LopezPerez et al., 2019). This group of viruses shares the same architectural principles with the icosahedral tailed dsDNA bacteriophages of the order Caudovirales (Pietilä et al., 2013b). All three different tail structures 
initially characterized for bacteriophages, have been found among the archaeal viruses: long contractile (myoviruses), long non-contractile (siphoviruses), and short non-contractile tails (podoviruses) (Atanasova et al., 2012). Genomes of archaeal caudoviruses are mosaics of genes with different evolutionary histories and their gene contents and genome lengths differ considerably, and consequently, also differ their capsid sizes, making this group genetically very diverse (Krupovic et al., 2010a; Pietilä et al., 2013c; Sencilo et al., 2013; Dyall-Smith et al., 2019). Although their capsid structures are very conserved, their receptor binding proteins have a high genetic plasticity allowing them to adapt to new hosts. Particularly, archaeal myoviruses with contractile tails have very broad host ranges crossing the genus boundary (Atanasova et al., 2012; Atanasova et al., 2015c). Furthermore, several myoviruses were shown to encode an invertible tail fiber gene module, which allows these viruses to alternate between different variants of the tail fiber proteins with distinct host specificities (Rossler et al., 2004; Dyall-Smith et al., 2018; Dyall-Smith et al., 2019).

Both culture-independent and culture-dependent approaches indicate that haloviruses represent a globally distributed reservoir of orphan genes encoding novel functions (Aalto et al., 2012; Atanasova et al., 2012; Roux et al., 2016). In addition, many halophilic archaea carry proviruses in their chromosomes (Krupovic et al., 2010a; Dyall-Smith et al., 2011; Makarova et al., 2014; Liu et al., 2015; Maier et al., 2015; Demina et al., 2016a; Atanasova et al., 2018b). The co-evolution of viruses and host cells in the presence of high recombination frequency in halophilic microbes have resulted in a globally distributed complex network of viruses, proviruses, membrane vesicle, transposons, and plasmids sharing the common genetic pool and displaying dynamic interplay across time and space (Zhang et al., 2012; Forterre et al., 2014; Atanasova et al., 2015c; Liu et al., 2015; Iranzo et al., 2016b; Atanasova et al., 2018b; Dyall-Smith and Pfeiffer, 2018; Wang et al., 2018a; Wang et al., 2018b). Here we report on the isolation of four new haloarchaeal viruses from saline Lake Retba. Morphological and genomic characterization of these viruses allowed their tentative taxonomic assignments. The siphovirus HFTV1, to the best of our knowledge, is the first virus isolated on a Haloferax strain, and it should belong in the order Caudovirales with other archaeal and bacterial tailed dsDNA viruses. Bacterial and archaeal caudoviruses together with eukaryotic herpesviruses 
form the HK97-like virus lineage (Abrescia et al., 2012). The pleomorphic archaeal viruses might belong to a tentative new virus lineage comprising membrane vesicle-like archaeal viruses of the family Pleolipoviridae. Collectively, our results further expand the knowledge on the genomic diversity and host range of haloarchaeal viruses and provide insights into their genome evolution.

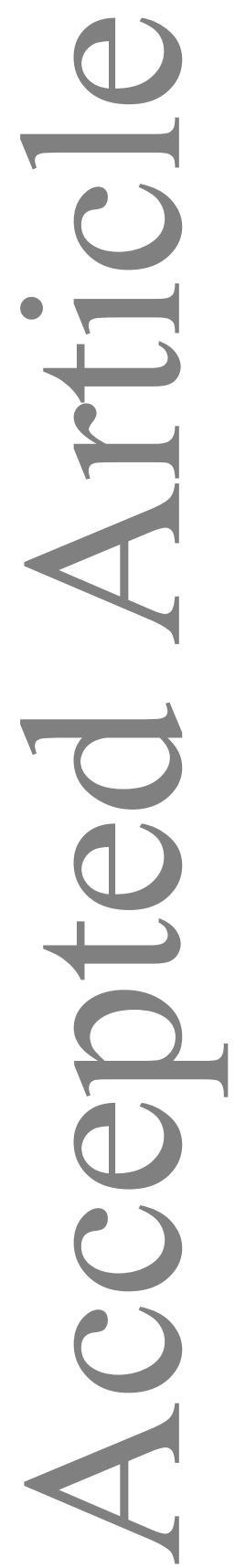




\section{Results and Discussion}

\section{Isolation of novel archaeal viruses of Halorubrum and Haloferax}

The viruses designated HRPV10, HRPV11, HRPV12 and HFTV1 were isolated together with their host strains from saline Lake Retba $\left(14^{\circ} 50^{\prime} 14^{\prime \prime} N, 17^{\circ} 14^{\prime} 55^{\prime \prime}\right.$ W), close to Dakar, the capital of Senegal, in May, 2011 (Table 1). Sample LR1 collected from the center of the Lake Retba contained grey water and a grey sediment mixed with salt, whereas sample LR2 (purple water with white sediment) was collected close to the site where salt is collected for trade. The salinity of the LR1 and LR2 samples was $290-300 \mathrm{~g} / \mathrm{L}$ and 250 $\mathrm{g} / \mathrm{L}$, respectively, whereas the temperature $\left(27^{\circ} \mathrm{C}\right)$ and $\mathrm{pH}(7.8)$ were the same at both sampling sites.

The haloarchaeal isolates were obtained by directly plating of the samples on MGM plates (see Methods). The obtained colonies were colony-purified on solid media. The pure cultures of the isolated halophilic archaeal strains (19 in total) were identified as members of the class Halobacteria by partial 16S rRNA gene sequence analysis (Fig. 1, Table 2). The isolates belong to three of the six families of the class Halobacteria: Halorubraceae (11 isolates), Haloferacaceae ( 7 isolates) and Halobacteriaceae (1 isolate). All isolates from (1) Halorubraceae were identified as Halorubrum spp., eight of which form a clade with Halorubrum lacusprofundi.

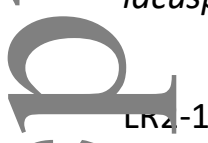

-19 clusters with Hrr. sodomense. LR1-22 clusters with an uncharacterized species of Halorubrum and LR2-20 did not cluster with any other strain. Among the isolates within Haloferacaceae, all seven were classified as Haloferax spp., clustering with Hfx. volcanii. LR2-15, the only representative of Halobacteriaceae, clustered with Halomicroarcula limicola and was classified as Halomicroarcula sp. LR215. The viruses were isolated on the endogenous Lake Retba strains (Table 2) using the same Lake Retba samples (see Methods for details). The host strains of the viruses HRPV10, HRPV11, and HRPV12 are Halorubrum spp. LR2-17, LR2-12, and LR1-23, respectively (Table 1), whereas HFTV1 infects Haloferax sp. LR2-5, making HFTV1 the first known virus isolated on Haloferax strain. The defective proviruses identified in Hfx. mediterranei (Li et al., 2013) and a variant of Halorubrum virus HF1 capable of infecting Hfx. volcanii 
[(Nuttall and Dyall-Smith, 1993) not available to our knowledge, personal communication], are the only reports on Haloferax viruses.

HRPV10, HRPV11, and HRPV12 produce hazy plaques that are 3-10 $\mathrm{mm}$ in diameter, whereas the HFTV1 plaques are clear (Table 1; Supplementary Fig. 1). The virus isolate plaque morphologies were different from each other, and HRPV10 and HRPV11, in particular, produce very hazy plaques difficult to document as figures, but they are visible in optimal lightning conditions (Supplementary Fig. 1A and B). The plaque rop morphologies of the HRPV10, HRPV11, and HRPV12 resemble the plaques of the members in the family Pleolipoviridae suggesting that also the plaques of the new pleomorphic virus isolates have non-lytic life cycle and the plaque is a consequence of the host cell growth retardation due to the virus infection (Pietilä et al., 2009; Svirskaite et al., 2016). The plaques were purified by three consecutive time to obtain pure virus cultures (see Methods). The virus stocks gave typical titers of $10^{11}-10^{12} \mathrm{pfu} / \mathrm{ml}$ (Table 1 ), suggesting that they might be promising model systems for studies on haloarchaeal virus functions and virus-host ( interactions. Infectivity of the viruses remained unchanged at $4{ }^{\circ} \mathrm{C}$ for a period of four weeks (data not Shown).

For virus purification, virions were collected from the virus stocks by using two-step polyethylene glycol(1) $\mathrm{NaCl}$ precipitation and purified to near homogeneity by rate zonal centrifugation in sucrose followed by equilibrium centrifugation in $\mathrm{CsCl}$. In the case of HRPV10, HRPV11 and HRPV12, this approach yielded highly pure virion preparations based on the specific infectivities $\left(2-5 \times 10^{13} \mathrm{pfu} / \mathrm{mg}\right.$ of protein; Table 3), negative staining and transmission electron microscopy (TEM) analysis of the purified particles (Fig. 2A-C), and SDSPAGE gel analysis (Fig. 3A-C). Specific infectivities and protein patterns of the purified HRPV10, HRPV11, and HRPV12 viruses were comparable with data reported for pleomorphic viruses purified by using the comparable precipitation and preparative ultracentrifugation techniques (e.g. viruses HRPV-1, HRPV-2, HRPV-3, HRPV-6, HHPV-1, His2, and HHPV4) yielding highly pure virus material (specific infectivities 2$5 \times 10^{13} \mathrm{pfu} / \mathrm{mg}$ of protein) (Pietilä et al., 2012; Atanasova et al., 2018b). HFTV1 virus particles were purified 
in high numbers based on TEM (Fig. 3D) and protein quantities (Table 3) but the purified particles had specific infectivity of $\sim 2 \times 10^{9} \mathrm{pfu} / \mathrm{mg}$ of protein (Table 3 ), which is 3-4 magnitudes lower than e.g. the specific infectivities of the purified virus samples of haloarchaeal tailed virus HSTV-1 $\left(\sim 9 \times 10^{12} \mathrm{pfu} / \mathrm{mg}\right.$ of protein) and icosahedral membrane-containing virus HCIV-1 ( $1 \times 10^{12} \mathrm{pfu} / \mathrm{mg}$ of protein), of which have been analyzed structurally (Pietilä et al., 2013b; Demina et al., 2016b; Santos-Perez et al., 2019). The negative staining and TEM of the purified HFTV1 particles revealed that some of particles had lost their genome explaining partly the loss of infectivity (Fig. 2D).

The purified HRPV10, HRPV11 and HRPV12 virions were tailless round particles with a diameter of $55 \mathrm{~nm}$ (Fig. 2A-C). The virion morphologies resembled one another and those of viruses in the family Pleolipoviridae (Pietilä et al., 2012). All three virion types equilibrated in $\mathrm{CsCl}$ density gradients (mean density of $1.30-1.35 \mathrm{~g} / \mathrm{ml}$ ) suggested that they contain lipids as one of their structural components. HRPV11 and HRPV12 were sensitive to chloroform, a widely used organic solvent, whereas HRPV10 was resistant (Table 1). Infectivity of all three viruses in the presence of non-ionic detergents Nonidet P-40 or Triton X100 decreased by $7-11$ orders of magnitude (Table 1 ).

(1)

The lipid compositions of the viruses and their host strains were verified by thin-layer chromatography and ammonium molybdate staining. The major polar lipids of Haloarcula hispanica - phosphatidylglycerol (PG), phosphatidylglycerophosphate methyl ester (PGP-Me), phosphatidylglycerosulfate (PGS), and triglycosyl glycerodiether (TGD) - have been previously identified (Bamford et al., 2005) and were used as a control (Fig. 3A-C). The patterns of lipid species of Halorubrum sp. LR2-17, LR2-12, and LR1-23 were identical to each other, containing probably PG, PG-Me and PGS (Fig. 3A-C). In all three viruses, lipids were found to be a structural component of the virions (Fig. 3A-C). The virus lipid profiles were identical with each other and resembled the lipid profiles of their respective hosts suggesting that viruses use non-selective lipid uptake as also shown previously for other pleolipoviruses (Pietilä et al., 2010; Pietilä et al., 2012). Virions of all 
three viruses contained two major structural protein species, which were $\sim 60 \mathrm{kDa}$ and $\sim 7 \mathrm{kDa}$ in mass when resolved in polyacrylamide gel (Fig. 3D-F). The patterns were different from each other and the major structural proteins were identified based on the gene homology to those of other pleolipoviruses (see below).

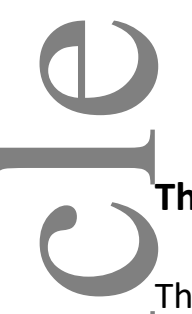

\section{Three new pleomorphic viruses are members of the genus Betapleolipovirus}

The nucleic acids extracted from the purified virions of HRPV10, HRPV11, and HRPV12 were sensitive to RQ1 DNase and Exonuclease III, resulting in complete degradation or extensive fragmentation, respectively. 8 Mung bean nuclease, which is specific to ssDNA (Fig. 4A), digested the HRPV10, HRPV11, and HRPV12 genomes into discrete fragments (Fig. 4B-D), suggesting that the genomes are dsDNA molecules with nicks or single-stranded regions. Sequencing of the genomes and assembly of the reads using a de novo assembly algorithm (with default parameters) implemented in the CLC Genomics Workbench (QIAGEN Bioinformatics) resulted in single contigs for each genome. Each contig contained direct terminal repeats of 18-20 bp. The sequencing reads overlapping both termini were as abundant as those from other genomic positions, indicating that the genomes are circular. Consistently, assembly of the sequencing reads with the SPAdes algorithm (Bankevich et al., 2012) resulted in contigs identical to those assembled with CLC Genomics Workbench, albeit with alternative start positions and terminal repeats, confirming the circular nature of the genomes (Supplementary Fig. 2).

To assess the relationship between the 3 new pleolipoviruses and the previously described members of the family Pleolipoviridae, we calculated intergenomic distances between pairs of viruses by pairwise comparisons of their nucleotide sequences and constructed the corresponding phylogenomic tree using VICTOR(Fig. 5A), a Genome BLAST Distance Phylogeny method (Meier-Kolthoff and Goker, 2017). The clustering of the pleolipoviruses in the resultant tree is consistent with previous classification based on the presence of genes for the putative replication-initiation or DNA polymerase proteins and relatedness of the VP3-like proteins (Pietilä et al., 2016). HRPV10, HRPV11 and HRPV12 form a well-supported clade with 
members of the genus Betapleolipovirus, namely, Halorubrum virus HRPV-3 and Halogeometricum virus HGPV-1. The clade also includes Haloarcula virus HHPV3 and Natrinema virus SNJ2, two tentative members of the Betapleolipovirus genus (Liu et al., 2015; Bamford et al., 2017).

The genomes of HRPV10, HRPV11, and HRPV12 were 9296, 9368, and 9944 bp in length, respectively, and their GC\% contents were 55.2-55.7\%. Genomes were predicted to contain 13-16 ORFs oriented in both transcriptional directions forming at least two putative operons (Fig. 5B; Supplementary Table 1). Genomes of HRPV10, HRPV11 and HRPV12 are very similar to each over (92-95\% nucleotide identity over the whole ength), but different from other characterized pleolipoviruses. The most closely related virus HGPV1 shares $68 \%$ identity over just $14 \%$ of the genome as determined by BLASTN. Consistently, comparison of the HRPV10, HRPV11 and HRPV12 proteins against the proteomes of all other known pleolipoviruses has revealed betapleolipoviruses as the closest relatives, with the largest number of sequence matches to betapleolipoviruses HGPV-1 (gene 2, ORF5, ORF6, ORF7, ORF9, ORF13) and HRPV3 (ORF12 and ORF9), whereas ORF4 was most similar to the homolog encoded by alphapleolipovirus HHPV-2 (Supplementary Table 2). The presence of the signature gene encoding the putative replication protein (ORF11 in HRPV10) unequivocally relates HRPV10, HRPV11 and HRPV12 to betapleolipoviruses. However, single-gene phylogenies reconstructed for the core proteins, namely, spike protein (El Omari et al., 2019) (Supplementary Fig. 3A) and the putative NTPase (Supplementary Fig. 3B), were not entirely consistent with this assignment (Fig. 5A), most likely reflecting occasional recombination between pleolipoviruses belonging to different genera, consistent with previous observations (Wang et al., 2018a). Comparison of HRPV ORFs to the non-redundant protein sequence database reveal that the most similar sequences are found in the genomes of Halorubrum coriense, Halorubrum terrestre and Halorubrum sp. T3, indicating the presence of related proviruses within these organisms (Supplementary Table 1). Proviruses related to pleolipoviruses have been described in haloarchaeal strains (Liu et al., 2015; Demina et al., 2016a; Atanasova et al., 2018a; Wang et al., 2018a). 
The close genetic similarity between HRPV10, HRPV11 and HRPV12 allows tracing the evolutionary events which took place in a relatively recent past. In particular, HRPV11 and HRPV12 share two small genes (HRPV11-ORF9 and HRPV12-ORF9; HRPV11-ORF14 and HRPV12-ORF15), encoding putative DNA-binding proteins carrying zinc-binding domains, which are absent in HRPV10, whereas ORF13 of HRPV12 is not found in the two other viruses (Supplementary Table 1). Notably, the closest homolog of the latter gene is Jencoded by an uncultivated tailed haloarchaeal virus eHP-27 (51\% identity; E=3e-57) (Garcia-Heredia et al., 2012), followed by homologs from diverse haloarchaea. Given that HRPV12 ORF13, which encodes a putative AdoMet-dependent methyltransferase (Supplementary Table 1), is not present in any other pleolipovirus (Fig. 5B), in all likelihood, it has been introduced into the HRPV12 genome horizontally from an unrelated haloarchaeal virus, following the divergence of HRPV12 from a common ancestor with HRPV10 and HRPV11. By contrast, the homolog of HRPV11 ORF9 has been apparently lost from the HRPV10 genome due to an inactivating point mutation, resulting in a long intergenic region between ORFs 8 and 9 . Furthermore, analysis of the nucleotide similarity pattern along the HRPV10, HRPV11 and HRPV12 genomes uncovered a hypervariable region within ORF4, which encodes for a putative receptor-binding spike protein, one of the two major virion proteins suggested to be involved in host recognition and virus entry (Pietilä et al., 2010). Notably, ORF4 homologs in HRPV11 and HRPV12 do not display appreciable similarity :thin the central region (Fig. 5B), pinpointing a highly variable protein domain, which is most likely to be critical for host recognition and binding; a similar conservation pattern is also observed in alphapleolipoviruses (e.g., compare HRPV-2 and HRPV-6 in Fig. 5B).

Comparative genomics analysis has shown that besides the five core genes conserved in all pleolipoviruses (except for His2, which contains four core genes), HRPV10, HRPV11 and HRPV12 encode several putative proteins specific to members of the genus Betapleolipovirus. These include homologs of HRPV10 ORF8 and ORF11, which are conserved in all currently known betapleolipoviruses, as well as ORF10 and ORF13, conserved in a subset of betapleolipoviruses, but not in viruses from the two other genera (Fig. 5B). Previous sequence analyses did not provide insights into the putative functions of the four conserved proteins. Indeed, HRPV10 ORF11-like proteins, which were suggested to represent replication initiation 
proteins of betapleolipoviruses (Krupovic et al., 2018), remain recalcitrant to functional annotation based on sequence similarity searches. However, profile-profile comparisons initiated with the sequence of HRPV10 ORF8 revealed homology to various PD-(D/E)XK family nuclease, including type II restriction endonucleases (Supplementary Table 1). Notably, the protein is not restricted to betapleolipoviruses, but is also conserved in several other groups of unrelated haloarchaeal viruses, including members of the Caudovirales (HHTV-1) and Sphaerolipoviridae (SH1, PH1, HCIV-1, HHIV-2). HRPV10 ORF10 and ORF13 encode putative DNA-binding proteins with winged helix-turn-helix and ribbon-helix-helix domains,

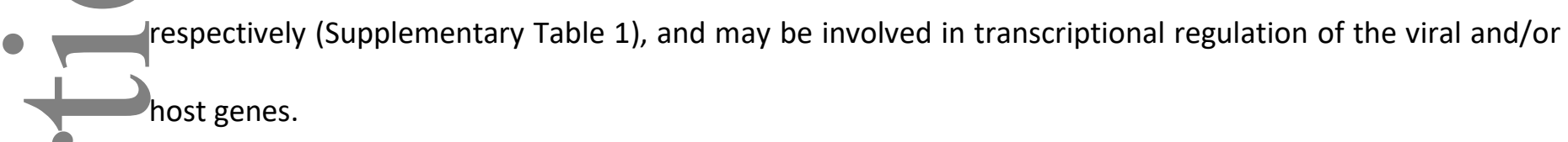

The first virus isolated on Haloferax has an icosahedral head, non-contractile tail and circularly permuted dsDNA genome

Micrographs of the purified HFTV1 virions revealed icosahedral particles with a long non-contractile tail typical of the siphovirus morphotype (Fig. 2D). The diameter of the head was $\sim 50 \mathrm{~nm}$ and the tail length was $\sim 60 \mathrm{~nm}$. The major protein species of HFTV1 virions were approximately 50, 40, 22 and $16 \mathrm{kDa}$ in mass (Fig. 3G). The infectivity of HFTV1 in the presence of chloroform, Nonidet P-40, or Triton X-100 remained (1) proteins and nucleic acid.

The nucleic acid extracted from purified HFTV1 virions was sensitive to RQ1 DNase treatment, but resistant to Exonuclease III and Mung bean nuclease, indicating that the genome is a dsDNA molecule (Supplementary Fig. 4). Genome sequencing and read assembly were performed as described above for pleolipoviruses and yielded a 38,059 bp-long circular contig (GC\% 54\%), which appears to represent a complete viral genome. A total of 70 ORFs were predicted in the HFTV1 genome using Prodigal (Hyatt et al., 2010), of which 28 (40\%) did not have any clear homologs in the public databases (Supplementary Table 3, Supplementary Fig. 5). Half (35) of the gene products had sequence similarity $(35-84 \%$ identity; 
Supplementary Table 3) to haloviruses: 15 to halophilic archaeal siphovirus HRTV-4 originating from a salt water sample from Margherita di Savoia, Italy (Sencilo et al., 2013), and 20 to uncultivated environmental haloviruses identified in the solar saltern of Santa Pola, Spain (Garcia-Heredia et al., 2012). The remaining $10 \%$ of the genes had closest homologs encoded in cellular organisms. Namely, the most significant similarities were shared with archaea from the order Halobacteriales (Natrialba, Natronobacterium, Haloarcula, Halococcus and Haloterrigena) and one to Cellulophaga baltica, a marine bacterium from the order Flavobacteriales (Supplementary Fig. 5). All ORFs but one are arranged in the same transcriptional direction (Fig. 6).

To determine the packaging mechanism employed by HFTV1, we analyzed the bias in distribution of the $1,657,094$ sequencing reads along the HFTV1 genome using PhageTerm, a tool that relies on the detection of biases in the number of sequencing reads observable at natural DNA termini compared with the rest of the viral genome (Garneau et al., 2017). The analysis revealed a pattern of sequencing read coverage consistent with a circularly permuted, terminally redundant genome and headful packaging mechanism initiated from a pac site, similar to that of bacteriophage P1 (Supplementary Fig. 6). Consistently, phylogeny of the large subunit of the terminase (Supplementary Fig. 3B), an enzyme responsible for genome packaging in bacterial and archaeal members of the order Caudovirales, revealed a relatively close relationship of HFTV1 to Halorubrum virus HRTV-4, a siphovirus for which the genome was also found to be circularly permuted (Sencilo et al., 2013).

The phylogenomic analysis using VICTOR (Meier-Kolthoff and Goker, 2017) confirmed the relationship of HFTV1 with Halorubrum virus HRTV-4, and also revealed relationship to four uncultivated viruses, eHP-1, eHP-15, eHP-19 and eHP-34 (Garcia-Heredia et al., 2012), for which the hosts have not been previously predicted (Supplementary Fig. 7A). The genomes of the latter viruses are generally collinear with those of HFTV1 and HRTV-4. The highest sequence similarity between the genomes is observed within the genes encoding for putative virion morphogenesis proteins, such as the major capsid protein, the large subunit of 
the terminase and tail proteins (Fig. 6). Given this genomic conservation, we predict that the uncultivated HFTV1-like viruses eHP-1, eHP-15, eHP-19 and eHP-34 infect halophilic archaea.

The genome of HFTV1 encodes several proteins putatively involved in DNA metabolism, namely a replicative minichromosome maintenance (MCM) helicase (gp58), DNA polymerase sliding clamp protein PCNA (gp64), DNA methyltransferase (gp61) and Rad52-like recombinase (gp50) (Fig. 6, Supplementary Table 3). The MCM is the principal helicase responsible for unwinding of the dsDNA duplex during chromosomal replication in archaea and eukaryotes (Bell and Botchan, 2013). MCM homologs have been previously identified in archaeal viruses and plasmids with moderately-sized genomes (20-50 kb) (Krupovic 1 et al., 2018) and phylogenetic analyses have suggested that mobile genetic elements have horizontally acquired the $\mathrm{mcm}$ genes from cellular organisms on multiple independent occasions (Krupovic et al., 2010b). The PCNA sliding clamp is another key replication protein in archaea and eukaryotes and is known as a "molecular tool-belt" due to its interaction with multiple other proteins involved in DNA replication and repair, including replicative DNA polymerase, DNA ligase, replication factor C, Flap Endonuclease 1 (FEN1) and RNase H (Pan et al., 2011). Similar to MCM helicases, PCNA homologs have been previously identified in some haloarchaeal virus genomes (Raymann et al., 2014), whereas certain other archaeal viruses have been shown to specifically recruit the host PCNA for the replication of their genomes (Gardner et al., 2014). Thus, the virus-encoded MCM and PCNA homologs are likely to orchestrate the replication of the HFTV1 genome.

Despite the synteny within the morphogenetic gene modules of HFTV1, HRTV-4, eHP-1, eHP-15, eHP-19, and eHP-34, the genome replication modules of these viruses appear to be very different. Namely, among the five viruses, only HFTV1 encodes both MCM helicase and PCNA. Notably, there is only one other known archaeal halophilic virus, podovirus HSTV-1, which harbors genes for both proteins in its genome (Pietilä et al., 2013b; Raymann et al., 2014). By contrast, the MCM helicase is encoded only by eHP-34, whereas HRTV-4, the closest relative of HFTV1, as well as eHP-1, eHP-15 and eHP-19 do not encode either of the two replication proteins. These observations reaffirm that virion formation and genome replication are 
uncoupled processes and evolve independently (Krupovic and Bamford, 2010), as is also evident in the case of pleolipoviruses, where viruses from the three genera encode non-homologous genome replication proteins (Krupovic et al., 2018). Consequently, viral genomes are often mosaics of genes with different evolutionary histories (Juhala et al., 2000; Pope et al., 2015; Iranzo et al., 2016a; Yutin et al., 2018).

Genetic mosaicism in tailed bacteriophage genomes is thought to be generated by illegitimate recombination (Krupovic et al., 2011a) or relaxed homologous recombination (De Paepe et al., 2014). The former occurs at essentially random positions within the genome, with nonviable recombinants being purged by natural selection (Pedulla et al., 2003). The latter process involves promiscuous phage-encoded 1 recombinases, such as phage $\lambda$ recombinase $\operatorname{Red} \beta$, which catalyze homologous recombination by annealing short and diverged sequences (De Paepe et al., 2014). Among the phage recombinases, the Rad52-like family is by far the largest and most diversified (Lopes et al., 2010). Interestingly, HFTV1 encodes a divergent member (gp50) of the Rad52-like family of recombinases (Rad52, PDB profile 5JRB_A, HHpred probability of $94 \%)$, which might facilitate genome remodeling in the replication modules of HFTV1-like viruses. Homologs of HFTV1 gp50 are also encoded by HRTV-4, eHP-1, eHP-15, and eHP-34 as well as by several other uncultivated halophilic viruses. Notably, the closest homologs of the HFTV1 PCNA are encoded by cellular organisms, suggesting that the corresponding gene has been acquired by HFTV1 from halophilic archaea, rather than inherited from a common ancestor shared with other viruses. Similarly, the closest homologs of the orthologous HFTV1 and eHP-34 MCM helicases are encoded by halophilic archaea, whereas homologs from other viral groups are more divergent. This suggests that the $p c n a$ and $m c m$ genes have been acquired directly from the hosts in different groups of archaeal viruses on several occasions, independently of each other.

\section{Narrow host range of haloarchaeal viruses from Lake Retba}

To determine the host range of viruses isolated from Lake Retba, we first tested their infectivity towards the 19 autochthonous haloarchaeal strains (Table 2). Despite the overall close genomic similarity, the 
pleomorphic viruses HRPV10, HRPV11, and HRPV12 were found to have distinct host ranges. HRPV11 displayed the broadest host range, being able to infect four different Halorubrum strains isolated from Lake Retba, whereas HRPV10 and HRPV12 each could infect only two different strains. Halorubrum sp. LR2-12 was susceptible to all three pleomorphic viruses, albeit with highly different efficiencies of plating (EOP) (Table 2). Notably, Haloferax virus HFTV1 was found to infect hosts across the genus boundary. In addition to its own isolation host, LR2-5, belonging to the genus Haloferax (Table 2), HFTV1 was able to infect Halorubrum sp. LR1-23, albeit with an eight orders of magnitude lower efficiency (Table 2). Similarly, a previous cross-infectivity study has shown that haloarchaeal siphoviruses generally display genus-restricted host ranges, although some isolates were found to infect hosts belonging to two or three genera (Atanasova et al., 2015c).

Next, we set out to explore the infectivity of the four viruses against Haloferax and Halorubrum strains isolated from geographically remote locations (Israel, Italy, Slovenia, Spain, Thailand and Antarctica). Namely, we tested 41 distinct Halorubrum strains originating from 10 different sampling sites and seven Haloferax strains from five distinct locations (Supplementary Table 4). Among the 51 strains tested, only Halorubrum sp. E200-4 isolated from Eilat, Israel was sensitive to pleomorphic virus HRPV11, albeit with a considerably lower $\left(\sim 6 \times 10^{-3}\right)$ EOP. This observation is consistent with the previous finding that most pleolipoviruses are highly specific to their isolation hosts (Atanasova et al., 2012; Atanasova et al., 2015c), but also indicates that occasional cross-infections that transcend site and time of isolation are possible. Similar patterns of infection, whereby viruses preferentially infect hosts from the same site rather than hosts isolated from similar but geographically remote sites, are also typical of bacterial virus-host systems from different ecological niches (Vos et al., 2009; Koskella et al., 2011), including hypersaline environments (Villamor et al., 2018). Thus, a pronounced biogeographical pattern emerges in haloarchaeal virus-host interactions, possibly due to increased diversification of the species composition of communities as a function of increasing geographic and environmental distance (Weitz et al., 2013). The specificity of viruses to autochthonous strains seemingly contrasts the conclusions drawn from comparative (meta)genomic analysis of halophilic viral communities which indicated that hypersaline viral communities should be 
considered as a genetic continuum across continents (Roux et al., 2016). Collectively, the results of the large-scale comparative genomics and local infectivity studies suggest that the gene complements responsible for virion formation and adaptation to environmental conditions are shared by haloarchaeal viruses across the globe, whereas the incessant evolutionary arms race drives local adaptation of viruses and their hosts at a finer scale.

Haloarchaeal myovirus isolates appear to display a broader host range (Atanasova et al., 2012; Atanasova et al., 2015c) than siphoviruses, such as HFTV1. This tendency appears to be general, because bacterial myoviruses also display broader host range than siphoviruses and podoviruses (Wichels et al., 1998). The 1 broader host range of archaeal myoviruses might be linked to the larger genomes and, accordingly, functionally more diverse gene content (Krupovic et al., 2018) including e.g. many auxiliary genes involved in DNA and RNA metabolism (Sencilo et al., 2013). For instance, HVTV-1 encodes an almost complete replisome (Pietilä et al., 2013c; Kazlauskas et al., 2016), whereas HGTV-1 encodes an RNA ligase and lysyltRNA synthetase and has 36 tRNA genes for all universal genetic code amino acids (Sencilo et al., 2013).

Presumably, this extended gene baggage renders myoviruses more promiscuous and partly independent of $+1$ the corresponding cellular machineries compared to viruses with smaller genomes.

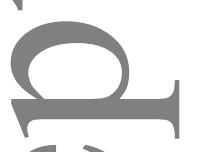

Scarcity of haloarchaeal virus isolates in the environment

The relative abundance of viruses in any particular sample or environment can be estimated by mapping the sequence reads from a metavirome to the reference genomes and expressed as Reads recruited Per $\mathbf{K b}$ of genome per $\mathbf{G b}$ of metagenome (RPKG). We used this approach to compare the relative abundance of the four viruses described in this study to that of the previously reported cultivated and uncultivated haloarchaeal viruses. To this end, we analyzed saltern viromes sequenced from Lake Retba (Roux et al., 2016) and South Bay Salt Works (Rodriguez-Brito et al., 2010). Notably, the samples for the preparation of the Lake Retba virome (Roux et al., 2016) were collected during the same sampling trip as those used to isolate viruses reported herein. However, none of the cultivated haloarchaeal viruses, including those 
described here, were sufficiently similar to the sequences present in the available viromes. By contrast, uncultured viruses predicted to infect Haloquadratum walsbyi recruited around 15,000 RPKG and formed a distinct clade in the phylogenomic tree (Supplementary Fig. 7). Apart from these, other uncultured viruses with no identified host and one virus predicted to infect nanohaloarchaea have recruitment of around 10 RPKG. The fact that all currently cultured viruses recruit only negligible number of reads, even when the virome originates from the same site as virus isolates is likely to reflect the still scarce and biased sampling of the (halo)archaeal virome. At least in the case of the Lake Retba viruses and the corresponding virome, the two have been isolated at the same time and thus temporal variation in virus diversity cannot explain this result. Given the low abundance of Halorubrum spp. in salterns from warm environments (GarciaHeredia et al., 2012), the currently used culture-based approaches appear to be biased towards isolation of viruses that represent a rather minor fraction of the natural haloarchaeal virome. We note, however, that Halorubrum species represent one of the dominant components of the haloarchaeal communities in the cold hypersaline environments, such as Deep Lake in Antarctica (DeMaere et al., 2013); thus, Halorubrum viruses might specifically dominate the cold-adapted haloarchaeal viromes. To obtain further insights into the actual diversity of haloarchaeal viruses and to initiate studies on the biology of ecologically relevant virus-host systems, future work should focus on improving the cultivation protocols for the dominant Wabitants of the hypersaline environments, such as Haloquadratum spp. (Oh et al., 2010; Dyall-Smith et al., 2011). Nevertheless, further characterization of the "cultivable minority" component of the haloarchaeal virome, as described in this study, provides important insights into the general mechanisms of haloarchaeal virus evolution and might lead to the establishment of virus-host systems in genetically $\overbrace{1}^{\text {tra }}$ 


\section{Experimental Procedures}

\section{Sampling and growth conditions}

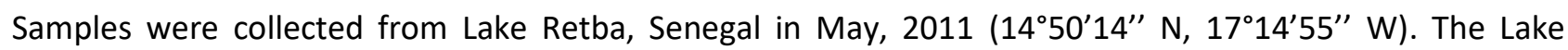
Retba sample 1 (LR1) was collected in the center of the lake, where salt was precipitated at the bottom. LR1 sample contained grey water with grey sediment mixed with salt. The Lake Retba sample 2 (LR2) consists of purple water with white salt sediment. The temperature, $\mathrm{pH}$, and salinity of the water at the sampling site was measured at the time of the sampling.

Isolation of microorganisms and viruses was carried out during the summer and autumn 2011. For isolation,

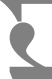
the liquid phase and the sediment (including precipitated salt) were separated by decanting. Water was transferred to clean bottles. The sediments were dissolved by adding of $6 \% \mathrm{SW}$ buffer (see below) until salts dissolved at the room temperature (magnetic stirring). Liquid phase and the dissolved sediment were treated as one sample.

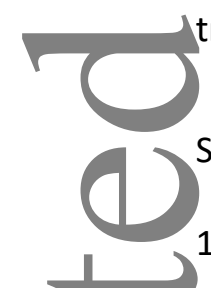

Strains and viruses were aerobically grown in modified growth medium (MGM) (Nuttall and Dyall-Smith, $1993)$ at $37^{\circ} \mathrm{C}$. For plaque assay, different dilutions of virus sample were mixed with host culture (300 $\mu$ l) and melted top layer agar $(3 \mathrm{ml})$ and plated on MGM plates. For plaque assay, the hosts were grown for 2-3 Over nights to obtain stationary phase culture. For making of MGM, 30\% saltwater (SW) containing $240 \mathrm{~g}$ $\mathrm{NaCl}, 30 \mathrm{~g} \mathrm{MgCl}_{2} \times 6 \mathrm{H}_{2} \mathrm{O}, 35 \mathrm{~g} \mathrm{MgSO}_{4} \times 7 \mathrm{H}_{2} \mathrm{O}, 7 \mathrm{~g} \mathrm{KCl}, 5 \mathrm{ml}$ of $1 \mathrm{M} \mathrm{CaCl}_{2} \times 2 \mathrm{H}_{2} \mathrm{O}$, and $80 \mathrm{ml}$ of $1 \mathrm{M} \mathrm{Tris}-\mathrm{HCl} \mathrm{pH}$ 7.2 (per liter of water) was prepared as described in the Halohandbook (Dyall-Smith, 2009). One litre of MGM medium contained $5 \mathrm{~g}$ of peptone (Oxoid), and $1 \mathrm{~g}$ of Bacto yeast extract (Becton, Dickinson and Company). Top layer, solid, and liquid medium contained $18 \%$ SW, $20 \%$ SW, and $23 \%$ SW, respectively. For the top layer and solid media, $4 \mathrm{~g}$ or $14 \mathrm{~g}$ of Bacto agar (Becton, Dickinson and Company) was added, respectively. 


\section{Isolation of microorganisms, 16S rRNA gene sequencing and phylogenetic tree}

To isolate strains from the samples, aliquots of samples $(100 \mu l)$ were directly plated on MGM plates and grown at $37^{\circ} \mathrm{C}$ in a covered box. A selection of colonies with different morphologies and colors were picked and colony purified by streaking single colonies on solid media by three consecutive times. The archaeal strains used in the study are listed in Table 2. The strains were identified based on their partial 16S rRNA gene sequences, which were determined as described previously (Sime-Ngando et al., 2011). The 16S rRNA genes were amplified by PCR. The primers were either universal for both the bacteria and archaea, or specific for the archaea (Eder et al., 1999). The sequences of the universal prokaryotic forward primers were 5'-AGAGTTTGATCCTGGCTCAG-3' (F27) and 5'-TCCGTGCCAGCAGCCGCCG -3' (F530), and those of the universal prokaryotic reverse primers were 5'-ACGGHTACCTTGTTACGACTT-3' (1512uR) and 5'CGTATTACCGCGGCTGCTGG-3' (R518). The archaea-specific primers were 5'-TCYGGTTGATCCTGCC-3' (8aF) and 5'-AGGAGGTGATCCAGCC-3' (AR1456). The reaction mixture (50 $\mu$ l of total volume) contained $1 \mathrm{X} \mathrm{Taq}^{\mathrm{TM}}$ buffer (Promega, Madison, WI, USA), $1.5 \mathrm{mM} \mathrm{MgCl}_{2}$, dNTPs at a concentration of $0.2 \mathrm{mM}$ each, $1 \mathrm{U}$ of Taq polymerase, each primer at a concentration of $125 \mathrm{pmol}$, and $5 \mathrm{ng}$ of template DNA. The amplification was ended by an extension step for $10 \mathrm{~min}$ at $72^{\circ} \mathrm{C}$. Negative and positive controls were included. Five $\mu$ l of PCR products were loaded onto $0.8 \%$ agarose gel in TAE $1 \mathrm{X}$ (Tris-acetic acid-EDTA buffer) and visualized under

UV light after ethidium bromide staining. PCR products obtained were cloned using TOPO TA cloning kit (Invitrogen, Carlsbad, CA, USA) according to the manufacturer's protocol. After blue-white selection, positive clones were grown at $37^{\circ} \mathrm{C}$ overnight on 96-well tissue culture plates in the presence of kanamycin.

The clones were picked and suspended in TE followed by boiling at $96^{\circ} \mathrm{C}$, and used as a template DNA for PCR amplification using M13 primers targeting the cloning vector (5'-GTAAAACGACGGCCAG-3' and 5'CAGGAAACAGCTATGAC-3'). The selected clones were grown as previously to extract plasmid DNA using Nucleospin Plasmid preparation Kit (Macherey-Nagel, EURL, France) and sent for Sanger sequencing using M13 primers on both strands. For a first classification, we used the SILVA r128 rRNA classifier (Pruesse et al., 2012). For the phylogenetic tree, sequences were aligned using MUSCLE (Edgar, 2004) and maximum 
likelihood trees were constructed using the program FastTree2 (Price et al., 2010). Bootstrapping (100 replicates) was performed using the Seqboot program in the PHYLIP package (Felsenstein, 1993).

The sequences are deposited in the NCBI data bank under the accession numbers MG462733-MG462751 (Table 2).

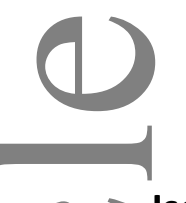

\section{Isolation of viruses}

Viruses were isolated either by direct plating or enrichment culture techniques. The pure cultures of LR1 $r(r)$ host strains (Table 2) were used to isolate viruses from LR1 samples. Hosts of LR2 (Table 2) were used to isolate viruses from LR2 samples. The LR1 and LR2 samples were first centrifuged at $13000 \mathrm{rpm}$ (Table-top Eppendorf centrifuge) for $10 \mathrm{~min}$ at room temperature and the supernatant we used for virus isolation. To remove microorganisms from the LR1 sediment sample, the sample was filtered (pore size $0.2 \mu \mathrm{m}$ ). For direct plating, $100 \mu \mathrm{l}$ of samples was mixed with dense host culture (300 $\mu \mathrm{l})$ and melted top layer agar (3 $\mathrm{ml}$ ) and poured on a plate, which was incubated at $37{ }^{\circ} \mathrm{C}$ until a dense lawn of archaea was observed (typically two to three days). For enrichments, $500 \mu \mathrm{l}$ of samples was mixed with host culture $(1 \mathrm{ml}$ grown for 2-3 days) and incubated in a shaker (200 rpm) 1-2 overnights. The enrichment samples (100 $\mu \mathrm{l}$ and 500 l) were plated as above. The obtained plaques were plaque purified. The plaque purification was carried out by growing the viruses on their host strain to obtain separate plaques by using plaque assay. Plaques were picked by sterile toothpick or Pasteur pipette, and a single plaque was resuspended in $0.5 \mathrm{ml}$ of MGM liquid medium. The plaque purification was repeated by using the single plaque as the starting material. The single plaque purification was carried out by three consecutive times for each virus.

For all plaque assays and preparation of the virus stocks, appropriate virus dilution $(100 \mu \mathrm{l})$ mixed with host culture $(300 \mu \mathrm{l})$ and melted top layer agar $(3 \mathrm{ml})$ was plated. The plates were incubated for 2-3 days. The virus stocks were prepared from semiconfluent plates. Top layer media from the semiconfluent plates were collected by a sterile glass triangle into a sterile Erlenmeyer bottle and $2 \mathrm{ml}$ of liquid medium was added per each collected plate. The suspension was incubated for 1.5 hours at $37^{\circ} \mathrm{C}$. Cell debris and agar were 
removed by centrifugation (Thermo Scientific F12 rotor, $8000 \mathrm{rpm}, 20 \mathrm{~min}, 5^{\circ} \mathrm{C}$ ). The supernatant was put into a clean bottle and it is referred as a virus stock. One semiconfluent plate produces approximately 3-3.5 $\mathrm{ml}$ of virus stock. Stability of viruses (virus stocks stored at $4{ }^{\circ} \mathrm{C}$ ) was monitored for four weeks by plaque assay. To test the sensitivity of the viruses to organic solvents and detergents, viruses (virus stock in MGM) were incubated in $20 \%(\mathrm{v} / \mathrm{v})$ chloroform, $0.1 \%(\mathrm{v} / \mathrm{v})$ Nonidet $\mathrm{P}-40$, or $0.1 \%$ Triton $\mathrm{X}-100$ for $15 \mathrm{~min}$ at $22^{\circ} \mathrm{C}$. MGM was used as a control. The infectivity of the viruses was determined by plaque assay and the experiments have been repeated at least for two times.

\section{Virus purification and particle analysis}

The virus stocks (typically made of 200 plates producing $600-700 \mathrm{ml}$ of virus stock or 400 plates producing $1200-1400 \mathrm{ml}$ of virus stock) were treated with DNase I (70 $\mathrm{\mu g} / \mathrm{ml} ; 30 \mathrm{~min}$ at $37^{\circ} \mathrm{C}$; Sigma-Aldrich) prior the purification. Viruses were precipitated from the virus stocks by using two-step polyethylene glycol (PEG)$\mathrm{NaCl}$ precipitation (Yamamoto et al., 1970). First, the impurities were precipitated by using 4\% (w/v) PEG 6000 (no $\mathrm{NaCl}$ added due to the high salinity of the virus stock). PEG was dissolved by magnetic stirring for $30 \mathrm{~min}$ at $4^{\circ} \mathrm{C}$. After centrifugation (Thermo Scientific F12 rotor, $8000 \mathrm{rpm}, 40 \mathrm{~min}, 5^{\circ} \mathrm{C}$ ), PEG was added to the supernatant to obtain a final concentration of $11 \%(\mathrm{w} / \mathrm{v})$. After dissolution of PEG and centrifugation (see above), the obtained virus precipitate was dissolved in $18 \%$ SW buffer followed by removal of the aggregates and undissolved components (Thermo Scientific F20 rotor, $7000 \mathrm{rpm}, 10 \mathrm{~min}, 5{ }^{\circ} \mathrm{C}$ ). Viruses were first purified by rate zonal ultracentrifugation in sucrose by using linear $5-20 \%$ sucrose gradients (18\% SW buffer; Sorvall rotor AH629, $24000 \mathrm{rpm}, 15^{\circ} \mathrm{C}$ ). The running times were $2.5 \mathrm{~h}$ (HRPV10), $1 \mathrm{~h} 45 \mathrm{~min}$ (HRPV11), and $3 \mathrm{~h}$ (HRPV12 and HFTV1). After rate zonal centrifugation, viruses were purified by

equilibrium centrifugation in $\mathrm{CsCl}$ gradients (mean $\rho=1.30-1.35 \mathrm{~g} / \mathrm{ml}$ in $18 \% \mathrm{SW}$; Sorvall rotor AH629, $20000 \mathrm{rpm}, 19 \mathrm{~h}, 20^{\circ} \mathrm{C}$ ), and concentrated by differential centrifugation (Sorvall rotor T647.5, $32000 \mathrm{rpm}$, 3-5 h, $15^{\circ} \mathrm{C}$ ). Virus purifications were repeated at least three times for each virus. Protein concentrations were determined by Bradford assay using bovine serum albumin as a standard (Bradford, 1976). The 
proteins were analyzed by using modified tricine-sodium dodecyl sulfate polyacrylamide gel electrophoresis (14\% acrylamide in the separation gel; (Schägger and von Jagow, 1987)). Gels were stained with Coomassie Brilliant Blue R 250 (Serva).

Viral lipids were isolated by chloroform-methanol extraction from the purified HRPV10, HRPV11, and HRPV12 virus particles and from the early-stationary-phase cells of Haloarcula hispanica (Juez et al., 1986) and Halorubrum sp. LR2-17, LR2-12, LR1-23 strains as previously described (Folch et al., 1957; Kates et al., 1972). Extracted lipids were dissolved in chloroform-methanol (9:1) and analyzed on pre-activated thin layer chromatography (TLC) silica plates, which were developed with chloroform-methanol-90\% acetic acid 1 (65:4:35 [vol/vol/vol]). Lipids were visualized by ammonium molybdate staining (Arnold et al., 2000). The plate was quickly dipped into a solution containing $10 \%(\mathrm{v} / \mathrm{v}) \mathrm{H}_{2} \mathrm{SO}_{4}$ and $5 \%(\mathrm{w} / \mathrm{v})$ ammonium molybdate, after which the excess liquid was dried, and the plate was incubated at $140{ }^{\circ} \mathrm{C}$ for around $15 \mathrm{~min}$.

For transmission electron microscopy, $5 \mu$ l samples of the purified virus particles were adsorbed on copper pioloform coated grids (Electron Microscopy Unit, HiLIFE Institute of Biotechnology, University of Helsinki). (1) The particles were negatively stained either with $3 \%(w / v)$ uranylacetate $(\mathrm{pH} 4.5)$ or $1 \%(\mathrm{w} / \mathrm{v})$ phosphotungstic acid (pH 7.0), and visualized by JEOL 1400 transmission electron microscope (Electron Microscopy Unit, HiLIFE Institute of Biotechnology, University of Helsinki) operating at $80 \mathrm{kV}$ acceleration voltage.

(

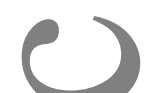

\section{Virus genome analysis, sequencing and annotation}

Nucleic acid was purified from the pure virus particles. The particles in $18 \% \mathrm{SW}$ were diluted 1:4 in $20 \mathrm{mM}$ Tris- $\mathrm{HCl}, \mathrm{pH} 7.2$ and treated with $1 \%(\mathrm{w} / \mathrm{v})$ sodium dodecyl sulphate and $100 \mu \mathrm{g} / \mathrm{ml}$ proteinase $\mathrm{K}$ (Thermo Scientific) in the presence of $1 \mathrm{mM}$ ethylenediaminetetraacetic acid (EDTA) for an hour at $37^{\circ} \mathrm{C}$. Nucleic acid was extracted by phenol-ether extraction and followed by precipitation with $\mathrm{NaCl}$ and ethanol. Purified nucleic acids were treated with RQ1 DNase (Promega), Exonuclease III (Fermentas), Mung bean nuclease (MBN $0.025,0.5$, or $5.0 \mathrm{U} / \mu \mathrm{g}$ DNA; Promega) according to manufacturers' instructions. For MBN 
experiments, phage $\phi X 174$ ssDNA genome and its dsDNA replicative form RFII (New England Biolabs) were used as controls.

Libraries were prepared using TruSeq PCRfree library preparation. Samples were sequenced by Illumina MiSeq 600 cycles (Illumina Inc., San Diego, CA) with 2x300 bp read length. The sequencing reads were trimmed based on the quality scores (limit 0.05) from a base-caller algorithm available in the sequencing files. The trimming was performed using the modified-Mott trimming algorithm implemented in the CLC Genomics Workbench v7 (QIAGEN Bioinformatics) and the trimmed reads were subsequently assembled into contigs using the same software with default parameters. Protein-coding genes were predicted using 1 Prodigal (Hyatt et al., 2010), and tRNA genes using tRNAscan-SE (Lowe and Eddy, 1997). Additional annotation of genes was done by comparing against the NCBI NR, COG (Tatusov et al., 2003), and TIGRfam (Haft et al., 2001) databases, and also manually annotated using HHPRED server (Zimmermann et al., 2018). The sequences are deposited in the NCBI GenBank data bank under the accession numbers MG550110 MG550113.

All pairwise comparisons of the nucleotide sequences were conducted using the Genome-BLAST Distance Phylogeny (GBDP) method (Meier-Kolthoff et al., 2013) under settings recommended for prokaryotic viruses (Meier-Kolthoff and Goker, 2017). All reference genomes were downloaded from https://www.ncbi.nlm.nih.gov/genome/browse/

Genome phylogenies were constructed using VICTOR (Meier-Kolthoff and Goker, 2017), a Genome BLAST Distance Phylogeny (GBDP) method which calculates intergenomic distances between pairs of viruses based on pairwise comparison of nucleotide sequences. The resulting intergenomic distances (including 100 replicates each) were used to infer a balanced minimum evolution tree with branch support via FASTME including SPR postprocessing (Lefort et al., 2015) for the formula D0. The trees were rooted at the outgroup and visualized with FigTree (Rambaut, 2006). For both single gene phylogenies, the sequences were aligned using MUSCLE (Edgar, 2004). Maximum likelihood trees were constructed using the program FastTree2 (Price et al., 2010). Bootstrapping was performed using the Seqboot program in the PHYLIP 
package (Felsenstein, 1993). Comparisons among related viral genomes and reference genomes were performed using tBLASTx or BLASTN (Edgar, 2010).

\section{Virus-host interaction studies}

Infectivity of HRPV10, HRPV11, HRPV12, and HFTV1 viruses was tested on 19 Lake Retba strains (Table 2)

nd 48 culture collection strains representing genus Halorubrum or Haloferax (Supplementary Table 3) by spot-on-lawn assay. Undiluted and diluted $\left(10^{-2}\right)$ virus stocks $(10 \mu \mathrm{l})$ were applied on the top layer agar Jinoculated with the test strain. The virus host strain and MGM medium were used as positive and negative controls. All positive results (growth inhibitions) were verified by plaque assay.

\section{Analysis of metaviromes}

Viromes were downloaded from Metavir 2 (Roux et al., 2014). Only sequence matches longer than $50 \mathrm{bp}$ withe-value less than $1 \mathrm{e}-5$ and more than $95 \%$ identity were considered. The recruitment of each genome from the virome was calculated by dividing the number of hits by the length of the contig (in $\mathrm{kb}$ ) and by the ize of the database (in Gb). This normalized measure is abbreviated as RPKG (Reads recruited Per Kb of genlome per $\mathbf{G b}$ of metagenome).

In order to test the performance of the currently available tools for identifying archaeal viruses in metagenomic dataset, we ran the VirSorter analysis (Roux et al., 2015) against the RefSeq virus database. Of the four genomes analyzed, only HFTV1 was considered by VirSorter to be of viral origin under the category 2 ("quite sure"), with three detected "phage hallmark genes". None of the pleolipoviruses was recognized as a virus, pointing to a need for improvement of the database of virus hallmark genes. 


\section{Acknowledgments}

This work was partly supported by Agence Nationale pour la Recherche grant \#ANR-17-CE15-0005-01 (project ENVIRA) to MK and the European Research Council (ERC) grant from the European Union's Seventh Framework Program (FP/2007-2013)/Project EVOMOBIL-ERC Grant Agreement no. 340440 to PF. CMM was supported by the European Molecular Biology Organization (ALTF 1562-2015) and Marie Curie Actions program from the European Commission (LTFCOFUND2013, GA-2013-609409). The use of the facilities and expertise of the Instruct-HiLIFE Biocomplex unit (Instruct Centre for Virus Production 2009-2017), member of Instruct-FI, is gratefully acknowledged. Academy of Finland and University of Helsinki are acknowledged for the support for the Instruct-FI. We thank Sari Korhonen and Soile Storman for skilled technical assistance and Mirka Lampi for help in virus purification. We are also grateful to Ying Liu for her help with HFTV1 genome annotation.

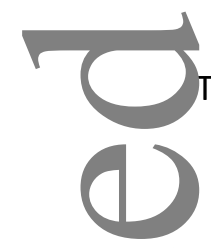

The authors have no conflict of interest to declare.

\section{References}

Aalto, A.P., Bitto, D., Ravantti, J.J., Bamford, D.H., Huiskonen, J.T., and Oksanen, H.M. (2012) Snapshot of virus evolution in hypersaline environments from the characterization of a membrane-containing Salisaeta icosahedral phage 1. Proc Natl Acad Sci U S A 109: 7079-7084.

Abby, S.S., Melcher, M., Kerou, M., Krupovic, M., Stieglmeier, M., Rossel, C. et al. (2018) Candidatus Nitrosocaldus cavascurensis, an ammonia oxidizing, extremely thermophilic archaeon with a highly mobile genome. Front Microbiol 9: 28.

Abrescia, N.G., Bamford, D.H., Grimes, J.M., and Stuart, D.I. (2012) Structure unifies the viral universe. Annu Rev Biochem 81: 795-822.

Ahlgren, N.A., Fuchsman, C.A., Rocap, G., and Fuhrman, J.A. (2019) Discovery of several novel, widespread, and ecologically distinct marine Thaumarchaeota viruses that encode amoC nitrification genes. ISME J: [Epub ahead of print].

Arnold, H.P., Zillig, W., Ziese, U., Holz, I., Crosby, M., Utterback, T. et al. (2000) A novel lipothrixvirus, SIFV, of the extremely thermophilic crenarchaeon Sulfolobus. Virology 267: 252-266.

Atanasova, N.S., Bamford, D.H., and Oksanen, H.M. (2015a) Haloarchaeal virus morphotypes. Biochimie 118: 333-343.

Atanasova, N.S., Oksanen, H.M., and Bamford, D.H. (2015b) Haloviruses of archaea, bacteria, and eukaryotes. Curr Opin Microbiol 25: 40-48.

Atanasova, N.S., Roine, E., Oren, A., Bamford, D.H., and Oksanen, H.M. (2012) Global network of specific virus-host interactions in hypersaline environments. Environ Microbiol 14: 426-440. 
Atanasova, N.S., Demina, T.A., Buivydas, A., Bamford, D.H., and Oksanen, H.M. (2015c) Archaeal viruses multiply: temporal screening in a solar saltern. Viruses 7: 1902-1926.

Atanasova, N.S., Demina, T.A., Krishnam Rajan Shanthi, S.N.V., Oksanen, H.M., and Bamford, D.H. (2018a) Extremely halophilic pleomorphic archaeal virus HRPV9 extends the diversity of pleolipoviruses with integrases. Res Microbiol 169: 500-504.

Atanasova, N.S., Heiniö, C.H., Demina, T.A., Bamford, D.H., and Oksanen, H.M. (2018b) The unexplored diversity of pleolipoviruses: the surprising case of two viruses with identical major structural modules. Genes (Basel) 9: 131.

Bamford, D.H., Pietilä, M.K., Roine, E., Atanasova, N.S., Dienstbier, A., Oksanen, H.M., and ICTV Report Consortium (2017) ICTV Virus Taxonomy Profile: Pleolipoviridae. J Gen Virol 98: 2916-2917.

Bamford, D.H., Ravantti, J.J., Rönnholm, G., Laurinavicius, S., Kukkaro, P., Dyall-Smith, M. et al. (2005) Constituents of SH1, a novel lipid-containing virus infecting the halophilic euryarchaeon Haloarcula hispanica. J Virol 79: 9097-9107.

Bankevich, A., Nurk, S., Antipov, D., Gurevich, A.A., Dvorkin, M., Kulikov, A.S. et al. (2012) SPAdes: a new genome assembly algorithm and its applications to single-cell sequencing. J Comput Biol 19: 455-477.

Bell, S.D., and Botchan, M.R. (2013) The minichromosome maintenance replicative helicase. Cold Spring Harb Perspect Biol 5: a012807.

Bradford, M.M. (1976) A rapid and sensitive method for the quantitation of microgram quantities of protein utilizing the principle of protein-dye binding. Anal Biochem 72: 248-254.

Crits-Christoph, A., Gelsinger, D.R., Ma, B., Wierzchos, J., Ravel, J., Davila, A. et al. (2016) Functional interactions of archaea, bacteria and viruses in a hypersaline endolithic community. Environ Microbiol 18: 2064-2077.

Cuadros-Orellana, S., Martin-Cuadrado, A.B., Legault, B., D'Auria, G., Zhaxybayeva, O., Papke, R.T., and Rodriguez-Valera, F. (2007) Genomic plasticity in prokaryotes: the case of the square haloarchaeon. ISME J 1: 235-245.

Danovaro, R., Dell'Anno, A., Corinaldesi, C., Rastelli, E., Cavicchioli, R., Krupovic, M. et al. (2016) Virusmediated archaeal hecatomb in the deep seafloor. Sci Adv 2: e1600492.

De Paepe, M., Hutinet, G., Son, O., Amarir-Bouhram, J., Schbath, S., and Petit, M.A. (2014) Temperate phages acquire DNA from defective prophages by relaxed homologous recombination: the role of Rad52like recombinases. PLoS Genet 10: e1004181.

DeMaere, M.Z., Williams, T.J., Allen, M.A., Brown, M.V., Gibson, J.A., Rich, J. et al. (2013) High level of intergenera gene exchange shapes the evolution of haloarchaea in an isolated Antarctic lake. Proc Natl 1. I Sci U S A 110: 16939-16944.

Demina, T.A., Atanasova, N.S., Pietilä, M.K., Oksanen, H.M., and Bamford, D.H. (2016a) Vesicle-like virion of Haloarcula hispanica pleomorphic virus 3 preserves high infectivity in saturated salt. Virology 499: 40-51.

Demina, T.A., Pietilä, M.K., Svirskaite, J., Ravantti, J.J., Atanasova, N.S., Bamford, D.H., and Oksanen, H.M. (2016b) Archaeal Haloarcula californiae icosahedral virus 1 highlights conserved elements in icosahedral membrane-containing DNA viruses from extreme environments. mBio 7.

Demina, T.A., Pietilä, M.K., Svirskaite, J., Ravantti, J.J., Atanasova, N.S., Bamford, D.H., and Oksanen, H.M. (2017) HCIV-1 and other tailless icosahedral internal membrane-containing viruses of the family Sphaerolipoviridae. Viruses 9.

Di Meglio, L., Santos, F., Gomariz, M., Almansa, C., Lopez, C., Anton, J., and Nercessian, D. (2016) Seasonal dynamics of extremely halophilic microbial communities in three Argentinian salterns. FEMS Microbiol Ecol 92.

Dyall-Smith, M. (2009). Halohandbook. URL http://www.haloarchaea.com/resources/halohandbook/

Dyall-Smith, M., and Pfeiffer, F. (2018) The PL6-family plasmids of Haloquadratum are virus-related. Front Microbiol 9: 1070.

Dyall-Smith, M., Pfeifer, F., Witte, A., Oesterhelt, D., and Pfeiffer, F. (2018) Complete genome sequence of the model halovirus phiH1 (phiH1). Genes (Basel) 9.

Dyall-Smith, M., Palm, P., Wanner, G., Witte, A., Oesterhelt, D., and Pfeiffer, F. (2019) Halobacterium salinarum virus ChaoS9, a Novel Halovirus Related to PhiH1 and PhiCh1. Genes (Basel) 10. 
Dyall-Smith, M.L., Pfeiffer, F., Klee, K., Palm, P., Gross, K., Schuster, S.C. et al. (2011) Haloquadratum walsbyi: limited diversity in a global pond. PLoS One 6: e20968.

Eder, W., Ludwig, W., and Huber, R. (1999) Novel 16S rRNA gene sequences retrieved from highly saline brine sediments of kebrit deep, red Sea. Arch Microbiol 172: 213-218.

Edgar, R.C. (2004) MUSCLE: multiple sequence alignment with high accuracy and high throughput. Nucleic Acids Res 32: 1792-1797.

Edgar, R.C. (2010) Search and clustering orders of magnitude faster than BLAST. Bioinformatics 26: 24602461.

El Omari, K., Li, S., Kotecha, A., Walter, T.S., Bignon, E.A., Harlos, K. et al. (2019) The structure of a prokaryotic viral envelope protein expands the landscape of membrane fusion proteins. Nat Commun 10: 846.

Erdmann, S., Tschitschko, B., Zhong, L., Raftery, M.J., and Cavicchioli, R. (2017) A plasmid from an Antarctic haloarchaeon uses specialized membrane vesicles to disseminate and infect plasmid-free cells. Nat Microbiol 2: 1446-1455.

Felsenstein, J. (1993) PHYLIP (phylogeny inference package), version 3.5 c: Joseph Felsenstein.

Folch, J., Lees, M., and Sloane Stanley, G.H. (1957) A simple method for the isolation and purification of total lipides from animal tissues. J Biol Chem 226: 497-509.

JForterre, P., Krupovic, M., Raymann, K., and Soler, N. (2014) Plasmids from Euryarchaeota. Microbiol Spectr 2: PLAS-0027-2014.

Garcia-Heredia, I., Martin-Cuadrado, A.B., Mojica, F.J., Santos, F., Mira, A., Anton, J., and Rodriguez-Valera, F. (2012) Reconstructing viral genomes from the environment using fosmid clones: the case of haloviruses. PLoS One 7: e33802.

Gardner, A.F., Bell, S.D., White, M.F., Prangishvili, D., and Krupovic, M. (2014) Protein-protein interactions leading to recruitment of the host DNA sliding clamp by the hyperthermophilic Sulfolobus islandicus rodshaped virus 2. J Virol 88: 7105-7108.

Garneau, J.R., Depardieu, F., Fortier, L.C., Bikard, D., and Monot, M. (2017) PhageTerm: a tool for fast and accurate determination of phage termini and packaging mechanism using next-generation sequencing data.

Sci Rep 7: 8292.

Gunde-Cimerman, N., Plemenitas, A., and Oren, A. (2018) Strategies of adaptation of microorganisms of the three domains of life to high salt concentrations. FEMS Microbiol Rev 42: 353-375.

Haft, D.H., Loftus, B.J., Richardson, D.L., Yang, F., Eisen, J.A., Paulsen, I.T., and White, O. (2001) TIGRFAMs: a protein family resource for the functional identification of proteins. Nucleic Acids Res 29: 41-43.

I... Itt, D., Chen, G.L., Locascio, P.F., Land, M.L., Larimer, F.W., and Hauser, L.J. (2010) Prodigal: prokaryotic gene recognition and translation initiation site identification. BMC Bioinformatics 11: 119.

Iranzo, J., Krupovic, M., and Koonin, E.V. (2016a) The double-stranded DNA virosphere as a modular hierarchical network of gene sharing. mBio 7: e00978-00916.

Iranzo, J., Koonin, E.V., Prangishvili, D., and Krupovic, M. (2016b) Bipartite network analysis of the archaeal virosphere: evolutionary connections between viruses and capsidless mobile elements. J Virol 90: 1104311055

Juez, G., Rodriguez-Valera, F., Ventosa, A., and Kushner, D.J. (1986) Haloarcula hispanica spec. nov. and Haloferax gibbonsii spec, nov., two new species of extremely halophilic archaebacteria. Syst Appl Microbiol 8: 75-79.

Juhala, R.J., Ford, M.E., Duda, R.L., Youlton, A., Hatfull, G.F., and Hendrix, R.W. (2000) Genomic sequences Of bacteriophages HK97 and HK022: pervasive genetic mosaicism in the lambdoid bacteriophages. $J \mathrm{Mol}$ Biol 299: 27-51.

Kates, M., Work, T.S., and Work, E. (1972) Techniques of Lipidology: Isolation, Analysis and Identification of Lipids. North-Holland, Amsterdam.

Kazlauskas, D., Krupovic, M., and Venclovas, C. (2016) The logic of DNA replication in double-stranded DNA viruses: insights from global analysis of viral genomes. Nucleic Acids Res 44: 4551-4564.

Koskella, B., Thompson, J.N., Preston, G.M., and Buckling, A. (2011) Local biotic environment shapes the spatial scale of bacteriophage adaptation to bacteria. Am Nat 177: 440-451.

Krupovic, M., and Bamford, D.H. (2010) Order to the viral universe. J Virol 84: 12476-12479. 
Krupovic, M., Forterre, P., and Bamford, D.H. (2010a) Comparative analysis of the mosaic genomes of tailed archaeal viruses and proviruses suggests common themes for virion architecture and assembly with tailed viruses of bacteria. J Mol Biol 397: 144-160.

Krupovic, M., Gribaldo, S., Bamford, D.H., and Forterre, P. (2010b) The evolutionary history of archaeal MCM helicases: a case study of vertical evolution combined with hitchhiking of mobile genetic elements. Mol Biol Evol 27: 2716-2732.

Krupovic, M., Prangishvili, D., Hendrix, R.W., and Bamford, D.H. (2011a) Genomics of bacterial and archaeal viruses: dynamics within the prokaryotic virosphere. Microbiol Mol Biol Rev 75: 610-635.

Krupovic, M., Spang, A., Gribaldo, S., Forterre, P., and Schleper, C. (2011b) A thaumarchaeal provirus testifies for an ancient association of tailed viruses with archaea. Biochem Soc Trans 39: 82-88.

Krupovic, M., Cvirkaite-Krupovic, V., Iranzo, J., Prangishvili, D., and Koonin, E.V. (2018) Viruses of archaea: structural, functional, environmental and evolutionary genomics. Virus Res 244: 181-193.

Lefort, V., Desper, R., and Gascuel, O. (2015) FastME 2.0: A Comprehensive, Accurate, and Fast DistanceBased Phylogeny Inference Program. Mol Biol Evol 32: 2798-2800.

Li, M., Liu, H., Han, J., Liu, J., Wang, R., Zhao, D. et al. (2013) Characterization of CRISPR RNA biogenesis and Cas6 cleavage-mediated inhibition of a provirus in the haloarchaeon Haloferax mediterranei. J Bacteriol 195: 867-875.

Liu, Y., Wang, J., Liu, Y., Wang, Y., Zhang, Z., Oksanen, H.M. et al. (2015) Identification and characterization of SNJ2, the first temperate pleolipovirus integrating into the genome of the SNJ1-lysogenic archaeal strain. Mol Microbiol 98: 1002-1020.

Lopes, A., Amarir-Bouhram, J., Faure, G., Petit, M.A., and Guerois, R. (2010) Detection of novel recombinases in bacteriophage genomes unveils Rad52, Rad51 and Gp2.5 remote homologs. Nucleic Acids Res 38: 3952-3962.

Lopez-Perez, M., Haro-Moreno, J.M., de la Torre, J.R., and Rodriguez-Valera, F. (2019) Novel Caudovirales associated with Marine Group I Thaumarchaeota assembled from metagenomes. Environ Microbiol: [Epub ahead of print].

Lowe, T.M., and Eddy, S.R. (1997) tRNAscan-SE: a program for improved detection of transfer RNA genes in genomic sequence. Nucleic Acids Res 25: 955-964.

Maier, L.K., Dyall-Smith, M., and Marchfelder, A. (2015) The adaptive immune system of Haloferax volcanii. Life (Basel) 5: 521-537.

Makarova, K.S., Wolf, Y.I., Forterre, P., Prangishvili, D., Krupovic, M., and Koonin, E.V. (2014) Dark matter in archaeal genomes: a rich source of novel mobile elements, defense systems and secretory complexes. r.wlemophiles 18: 877-893.

Meier-Kolthoff, J.P., and Goker, M. (2017) VICTOR: genome-based phylogeny and classification of prokaryotic viruses. Bioinformatics 33: 3396-3404.

Meier-Kolthoff, J.P., Auch, A.F., Klenk, H.P., and Goker, M. (2013) Genome sequence-based species delimitation with confidence intervals and improved distance functions. BMC Bioinformatics 14: 60.

Mizuno, C.M., Rodriguez-Valera, F., Kimes, N.E., and Ghai, R. (2013) Expanding the marine virosphere using metagenomics. PLoS Genet 9: e1003987.

Nuttall, S.D., and Dyall-Smith, M.L. (1993) HF1 and HF2: novel bacteriophages of halophilic archaea. Virology 197: 678-684.

Oh, D., Porter, K., Russ, B., Burns, D., and Dyall-Smith, M. (2010) Diversity of Haloquadratum and other haloarchaea in three, geographically distant, Australian saltern crystallizer ponds. Extremophiles 14: 161169.

Oren, A. (2002) Molecular ecology of extremely halophilic Archaea and Bacteria. FEMS Microbiol Ecol 39: 17.

Oren, A., Bratbak, G., and Heldal, M. (1997) Occurrence of virus-like particles in the Dead Sea. Extremophiles 1: 143-149.

Pagaling, E., Haigh, R.D., Grant, W.D., Cowan, D.A., Jones, B.E., Ma, Y. et al. (2007) Sequence analysis of an Archaeal virus isolated from a hypersaline lake in Inner Mongolia, China. BMC Genomics 8: 410.

Pan, M., Kelman, L.M., and Kelman, Z. (2011) The archaeal PCNA proteins. Biochem Soc Trans 39: 20-24. 
Pedulla, M.L., Ford, M.E., Houtz, J.M., Karthikeyan, T., Wadsworth, C., Lewis, J.A. et al. (2003) Origins of highly mosaic mycobacteriophage genomes. Cell 113: 171-182.

Philosof, A., Yutin, N., Flores-Uribe, J., Sharon, I., Koonin, E.V., and Beja, O. (2017) Novel abundant oceanic viruses of uncultured Marine Group II Euryarchaeota. Curr Biol 27: 1362-1368.

Pietilä, M.K., Atanasova, N.S., Oksanen, H.M., and Bamford, D.H. (2013a) Modified coat protein forms the flexible spindle-shaped virion of haloarchaeal virus His1. Environ Microbiol 15: 1674-1686.

Pietilä, M.K., Roine, E., Paulin, L., Kalkkinen, N., and Bamford, D.H. (2009) An ssDNA virus infecting archaea: a new lineage of viruses with a membrane envelope. Mol Microbiol 72: 307-319.

Pietilä, M.K., Laurinavicius, S., Sund, J., Roine, E., and Bamford, D.H. (2010) The single-stranded DNA genome of novel archaeal virus halorubrum pleomorphic virus 1 is enclosed in the envelope decorated with glycoprotein spikes. J Virol 84: 788-798.

Pietilä, M.K., Demina, T.A., Atanasova, N.S., Oksanen, H.M., and Bamford, D.H. (2014) Archaeal viruses and bacteriophages: comparisons and contrasts. Trends Microbiol 22: 334-344.

Pietilä, M.K., Roine, E., Sencilo, A., Bamford, D.H., and Oksanen, H.M. (2016) Pleolipoviridae, a newly proposed family comprising archaeal pleomorphic viruses with single-stranded or double-stranded DNA genomes. Arch Virol 161: 249-256.

Pietilä, M.K., Atanasova, N.S., Manole, V., Liljeroos, L., Butcher, S.J., Oksanen, H.M., and Bamford, D.H. (2012) Virion architecture unifies globally distributed pleolipoviruses infecting halophilic archaea. J Virol 86: 5067-5079.

Pietilä, M.K., Laurinmäki, P., Russell, D.A., Ko, C.C., Jacobs-Sera, D., Hendrix, R.W. et al. (2013b) Structure of the archaeal head-tailed virus HSTV-1 completes the HK97 fold story. Proc Natl Acad Sci U S A 110: 1060410609.

Pietilä, M.K., Laurinmäki, P., Russell, D.A., Ko, C.C., Jacobs-Sera, D., Butcher, S.J. et al. (2013c) Insights into head-tailed viruses infecting extremely halophilic archaea. J Virol 87: 3248-3260.

Pope, W.H., Bowman, C.A., Russell, D.A., Jacobs-Sera, D., Asai, D.J., Cresawn, S.G. et al. (2015) Whole genome comparison of a large collection of mycobacteriophages reveals a continuum of phage genetic diversity. Elife 4: e06416.

Prangishvili, D., Bamford, D.H., Forterre, P., Iranzo, J., Koonin, E.V., and Krupovic, M. (2017) The enigmatic archaeal virosphere. Nat Rev Microbiol 15: 724-739.

Price, M.N., Dehal, P.S., and Arkin, A.P. (2010) FastTree 2--approximately maximum-likelihood trees for large alignments. PLoS One 5: e9490.

Pruesse, E., Peplies, J., and Glockner, F.O. (2012) SINA: accurate high-throughput multiple sequence - i- nment of ribosomal RNA genes. Bioinformatics 28: 1823-1829.

Rambaut, A. (2006) FigTree 1.4.3 - a graphical viewer of phylogenetic trees and a program for producing publication-ready figures. In $\underline{\text { http://treebioedacuk/software/figtree/. }}$.

Raymann, K., Forterre, P., Brochier-Armanet, C., and Gribaldo, S. (2014) Global phylogenomic analysis disentangles the complex evolutionary history of DNA replication in archaea. Genome Biol Evol 6: 192-212.

Rodriguez-Brito, B., Li, L., Wegley, L., Furlan, M., Angly, F., Breitbart, M. et al. (2010) Viral and microbial community dynamics in four aquatic environments. ISME J 4: 739-751.

Rossler, N., Klein, R., Scholz, H., and Witte, A. (2004) Inversion within the haloalkaliphilic virus phi Ch1 DNA results in differential expression of structural proteins. Mol Microbiol 52: 413-426.

Roux, S., Enault, F., Hurwitz, B.L., and Sullivan, M.B. (2015) VirSorter: mining viral signal from microbial genomic data. PeerJ 3: e985.

Roux, S., Tournayre, J., Mahul, A., Debroas, D., and Enault, F. (2014) Metavir 2: new tools for viral metagenome comparison and assembled virome analysis. BMC Bioinformatics 15: 76.

Roux, S., Enault, F., Ravet, V., Colombet, J., Bettarel, Y., Auguet, J.C. et al. (2016) Analysis of metagenomic data reveals common features of halophilic viral communities across continents. Environ Microbiol 18: 889903.

Santos-Perez, I., Charro, D., Gil-Carton, D., Azkargorta, M., Elortza, F., Bamford, D.H. et al. (2019) Structural basis for assembly of vertical single beta-barrel viruses. Nat Commun 10: 1184.

Schägger, H., and von Jagow, G. (1987) Tricine-sodium dodecyl sulfate-polyacrylamide gel electrophoresis for the separation of proteins in the range from 1 to $100 \mathrm{kDa}$. Anal Biochem 166: 368-379. 
Sencilo, A., Paulin, L., Kellner, S., Helm, M., and Roine, E. (2012) Related haloarchaeal pleomorphic viruses contain different genome types. Nucleic Acids Res 40: 5523-5534.

Sencilo, A., Jacobs-Sera, D., Russell, D.A., Ko, C.C., Bowman, C.A., Atanasova, N.S. et al. (2013) Snapshot of haloarchaeal tailed virus genomes. RNA Biol 10: 803-816.

Sime-Ngando, T., Lucas, S., Robin, A., Tucker, K.P., Colombet, J., Bettarel, Y. et al. (2011) Diversity of virushost systems in hypersaline Lake Retba, Senegal. Environ Microbiol 13: 1956-1972.

Svirskaite, J., Oksanen, H.M., Daugelavicius, R., and Bamford, D.H. (2016) Monitoring physiological changes in haloarchaeal cell during virus release. Viruses 8: 59.

Söding, J., Biegert, A., and Lupas, A.N. (2005) The HHpred interactive server for protein homology detection and structure prediction. Nucleic Acids Res 33: W244-248.

Tang, S.L., Nuttall, S., and Dyall-Smith, M. (2004) Haloviruses HF1 and HF2: evidence for a recent and large recombination event. J Bacteriol 186: 2810-2817.

Tatusov, R.L., Fedorova, N.D., Jackson, J.D., Jacobs, A.R., Kiryutin, B., Koonin, E.V. et al. (2003) The COG database: an updated version includes eukaryotes. BMC Bioinformatics 4: 41.

Triantaphyllidis, G.V., Abatzopoulos, T.J., and Sorgeloos, P. (1998) Review of the biogeography of the genus Artemia (Crustacea, Anostraca). Journal of Biogeography 25: 213-226.

Tschitschko, B., Erdmann, S., DeMaere, M.Z., Roux, S., Panwar, P., Allen, M.A. et al. (2018) Genomic variation and biogeography of Antarctic haloarchaea. Microbiome 6: 113.

Wang, J., Liu, Y., Liu, Y., Du, K., Xu, S., Wang, Y. et al. (2018a) A novel family of tyrosine integrases encoded by the temperate pleolipovirus SNJ2. Nucleic Acids Res 46: 2521-2536.

Wang, Y., Chen, B., Cao, M., Sima, L., Prangishvili, D., Chen, X., and Krupovic, M. (2018b) Rolling-circle replication initiation protein of haloarchaeal sphaerolipovirus SNJ1 is homologous to bacterial transposases of the IS91 family insertion sequences. J Gen Virol 99: 416-421.

Weitz, J.S., Poisot, T., Meyer, J.R., Flores, C.O., Valverde, S., Sullivan, M.B., and Hochberg, M.E. (2013) Phage-bacteria infection networks. Trends Microbio/ 21: 82-91.

Ventosa, A., de la Haba, R.R., Sanchez-Porro, C., and Papke, R.T. (2015) Microbial diversity of hypersaline environments: a metagenomic approach. Curr Opin Microbiol 25: 80-87.

Wichels, A., Biel, S.S., Gelderblom, H.R., Brinkhoff, T., Muyzer, G., and Schutt, C. (1998) Bacteriophage diversity in the North Sea. Appl Environ Microbiol 64: 4128-4133.

Vik, D.R., Roux, S., Brum, J.R., Bolduc, B., Emerson, J.B., Padilla, C.C. et al. (2017) Putative archaeal viruses from the mesopelagic ocean. PeerJ 5: e3428.

Villamor, J., Ramos-Barbero, M.D., Gonzalez-Torres, P., Gabaldon, T., Rossello-Mora, R., Meseguer, I. et al. $1018)$ Characterization of ecologically diverse viruses infecting co-occurring strains of cosmopolitan hyperhalophilic Bacteroidetes. ISME J 12: 424-437.

Vos, M., Birkett, P.J., Birch, E., Griffiths, R.I., and Buckling, A. (2009) Local adaptation of bacteriophages to their bacterial hosts in soil. Science 325: 833.

Yamamoto, K.R., Alberts, B.M., Benzinger, R., Lawhorne, L., and Treiber, G. (1970) Rapid bacteriophage sedimentation in the presence of polyethylene glycol and its application to large-scale virus purification. Virology 40: 734-744.

Yutin, N., Backstrom, D., Ettema, T.J.G., Krupovic, M., and Koonin, E.V. (2018) Vast diversity of prokaryotic virus genomes encoding double jelly-roll major capsid proteins uncovered by genomic and metagenomic sequence analysis. Virol J 15: 67.

Zhang, Z., Liu, Y., Wang, S., Yang, D., Cheng, Y., Hu, J. et al. (2012) Temperate membrane-containing halophilic archaeal virus SNJ1 has a circular dsDNA genome identical to that of plasmid pHH205. Virology 434: 233-241.

Zimmermann, L., Stephens, A., Nam, S.Z., Rau, D., Kubler, J., Lozajic, M. et al. (2018) A completely reimplemented MPI bioinformatics toolkit with a new HHpred server at its core. J Mol Biol 430: 2237-2243. 


\section{Table and Figure legends}

Table 1. Viruses from Lake Retba

Table 2. Strains isolated from the Lake Retba samples

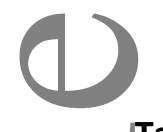

Table 3. Virus purification by PEG-NaCl precipitation, rate zonal, equilibrium and differential

ultracentrifugation

Figure 1. Maximum likelihood phylogenetic tree of the isolated Lake Retba strains based on the partial $16 \mathrm{~S}$ rRNA gene sequences. Isolates from Lake Retba (LR) are highlighted in red. Sequences were aligned using MUSCLE (Edgar, 2004) and the maximum likelihood tree was constructed using the FastTree2 program (Price et al., 2010). The numbers above the branches represent bootstrap support values from 100 replicates. The scale bar represents the number of substitutions per site.

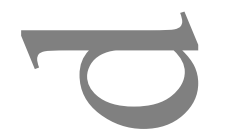

Figure 2. Transmission electron microscopy of purified viruses (A) HRPV10, (B) HRPV11, (C) HRPV12 (D) JHFTV1. (A-C) staining with uranyl acetate; (D) staining with phosphotungstic acid. HFTV1 particles devoid of DNA are indicated by arrows. Bars, $100 \mathrm{~nm}$.

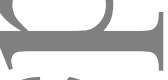

(1)

Figure 3. Lipid and protein analysis of virions. (A-C) A thin-layer chromatogram of lipids extracted from virus particles purified by PEG-NaCl precipitation, rate zonal (in sucrose) and equilibrium (in $\mathrm{CsCl}$ ) centrifugation and concentrated by differential centrifugation (A) HRPV10, (B) HRPV11, and (C) HRPV12 and their corresponding host strains. The corresponding band of each lipid species are marked by $1-4$. The major lipid species of Haloarcula hispanica $(\mathrm{Hh})$ are indicated on the right and their positions marked by the Roman numerals as follows: PG, phosphatidylglycerol (I); PGP-Me, phosphatidylglycerophosphate methyl ester (II); PGS, phosphatidylglycerosulfate (III); TGD, triglycosyl glycerodiether (IV). (D-G) SDS-PAGE analysis of the purified viruses (D) HRPV10, (E) HRPV11, (F) HRPV12, (G) HFTV1. Molecular mass marker is shown (M, kDa). 
Figure 4. Mung bean nuclease (MBN) analyses of (A) $\phi X 174$ single-stranded (ss) and double-stranded (ds) genomic DNA (B) HRPV10, (C) HRPV11, and (D) HRPV12. MBN amounts used are indicated as units (U) per $1 \mu \mathrm{g}$ of DNA. All reactions contained $300 \mathrm{ng}$ of DNA. Molecular mass marker (M) is indicated in kb.

Figure 5. HRPV10, HRPV11, HRPV12 and the members of the family Pleolipoviridae. (A) Phylogenomic tree was constructed using the Genome BLAST Distance Phylogeny (GBDP) strategy implemented in VICTOR (Meier-Kolthoff and Goker, 2017). The numbers above branches are GBDP pseudo-bootstrap support values from 100 replications. Clades corresponding to the genera Alphapleolipovirus, Betapleolipovirus and Gammapleolipovirus are colored light blue, beige, and grey, respectively. (B) Genomic comparison of pleolipoviruses depicted in panel A. Homologous genes are indicated with the same colors.

Figure 6. Genomic comparison of HFTV1, HRTV-4, eHP-4, eHP-15 and eHP-1. Open reading frames (ORFs)

(1) are depicted as arrows indicating the directionality of transcription. When possible, the predicted functions Jare indicated above the corresponding ORFs. Shading connecting the ORFs indicates the amino acid sequence identity between the corresponding protein products; the color key is provided at the bottom of the figure. Abbreviations: TerS and TerL, small and large subunits of the terminase, respectively; CBD, (1) carbohydrate-binding domain; PAPS, phosphoadenosine phosphosulfate; MCM, minichromosome maintenance helicase; PCNA, proliferating cell nuclear antigen; MTase, methyltransferase.

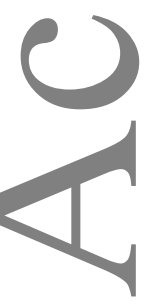




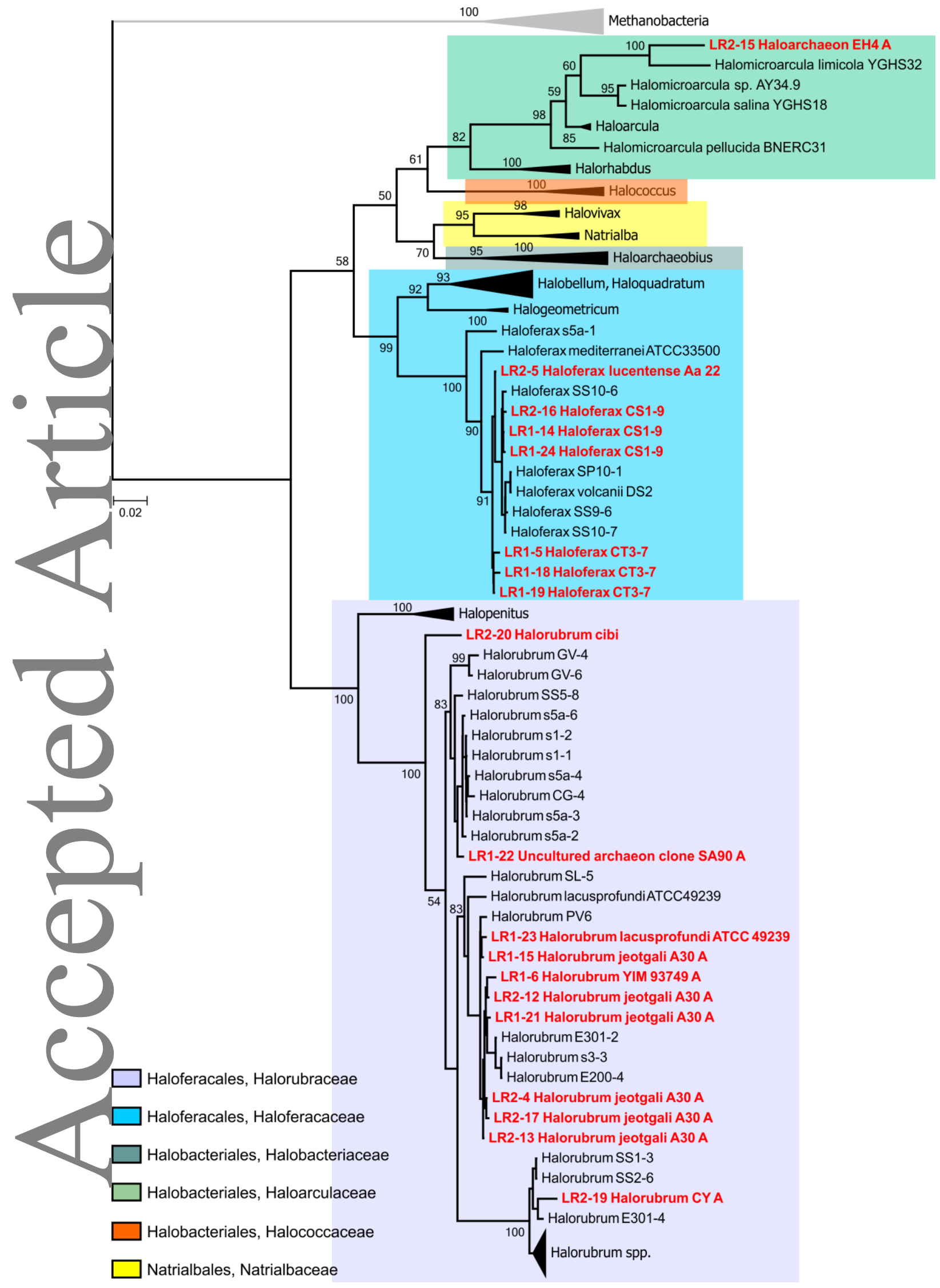

This article is protected by copyright. All rights reserved 

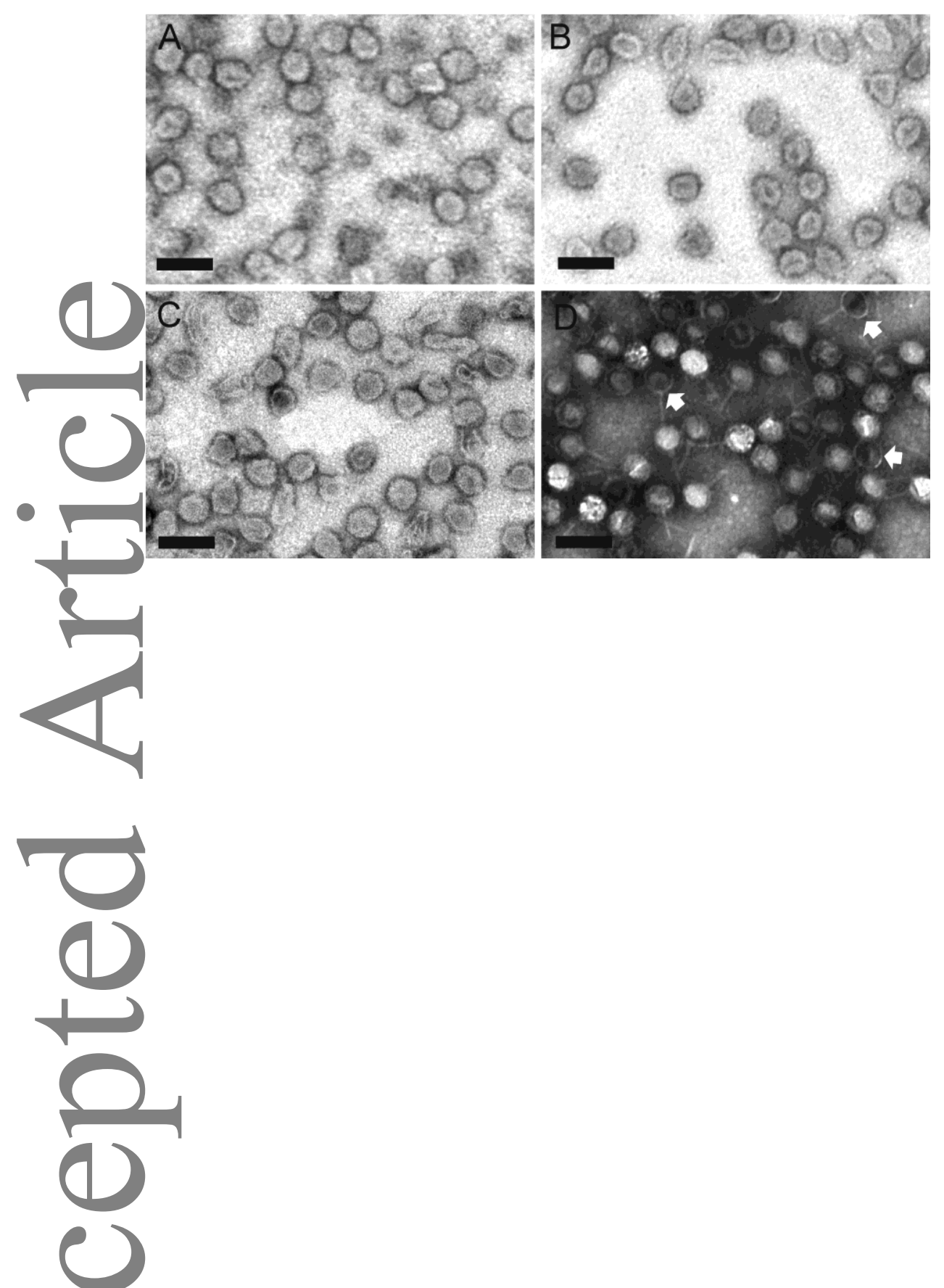

()

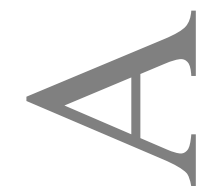




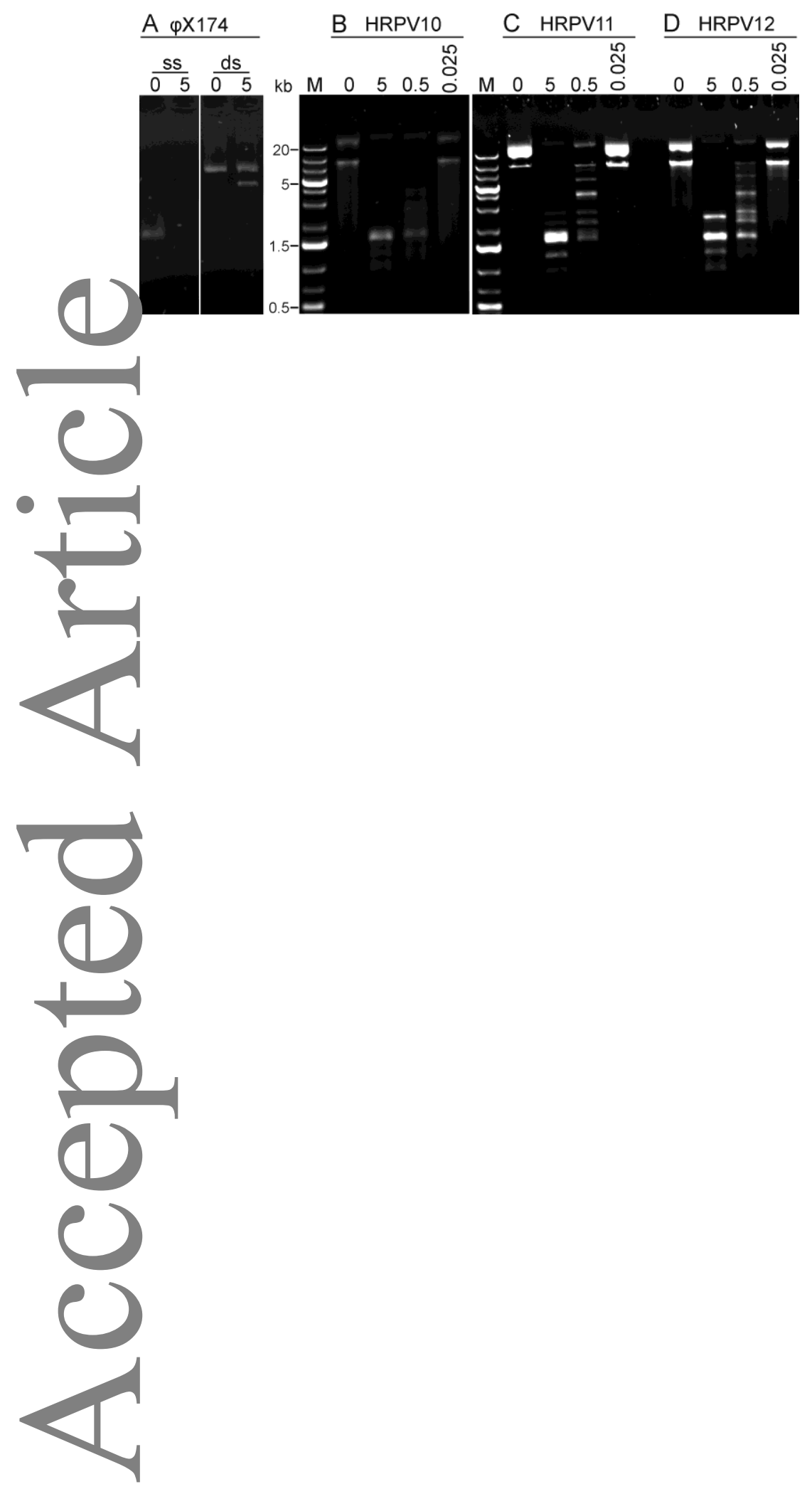


A

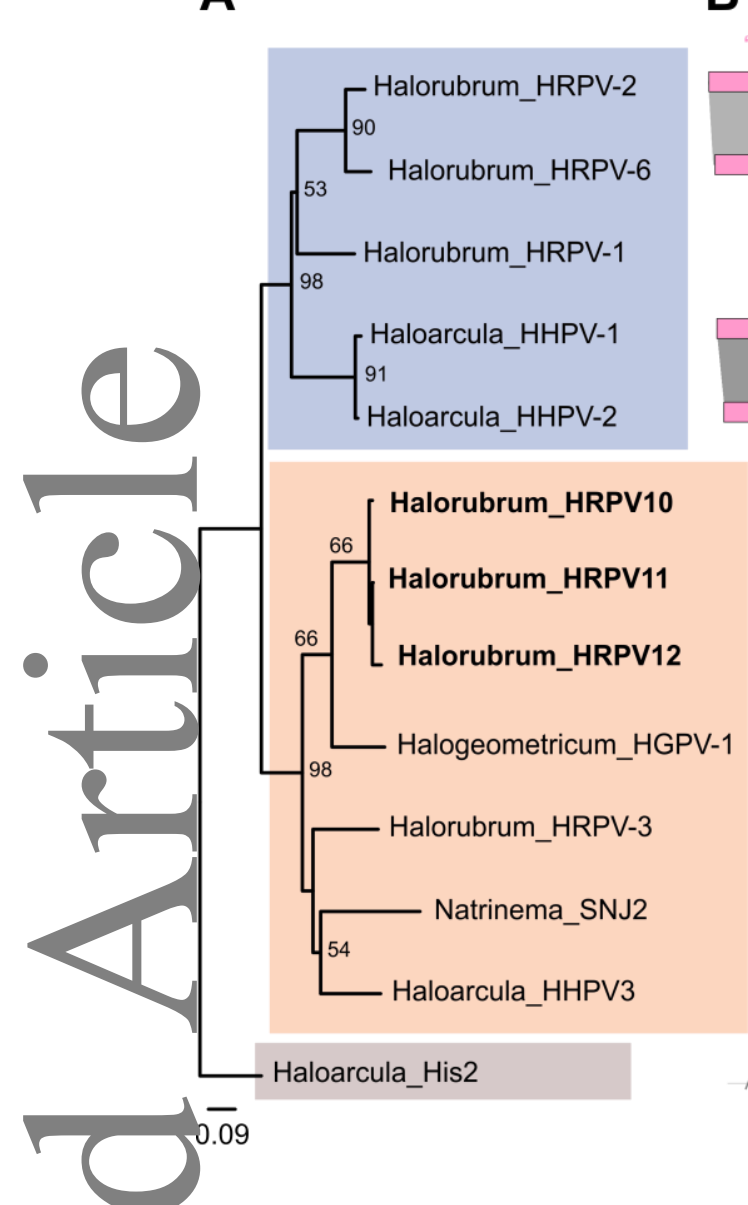

B
VP3-like VP4-like protein protein

VP8-like protein

"NTPase"

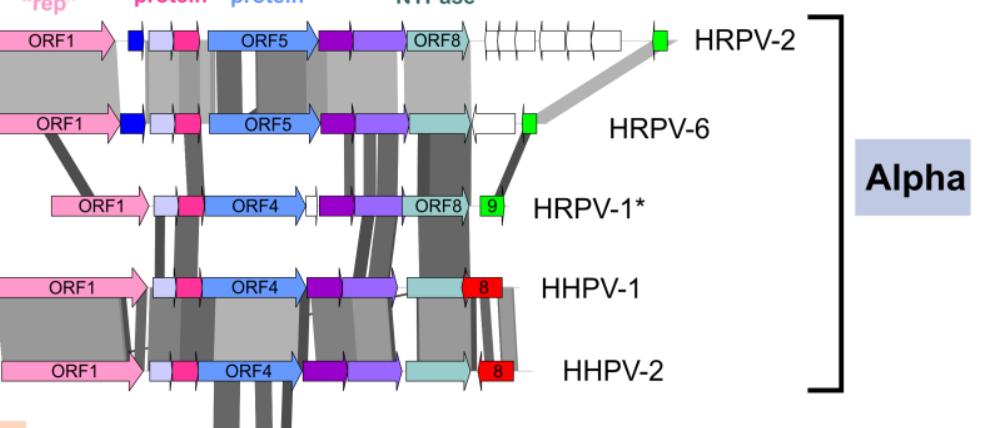

1) 1 ORF4

HRPV11

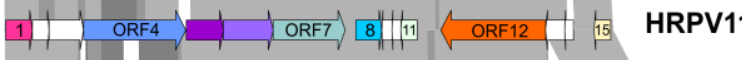

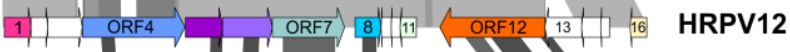

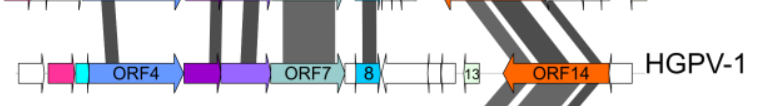

Beta
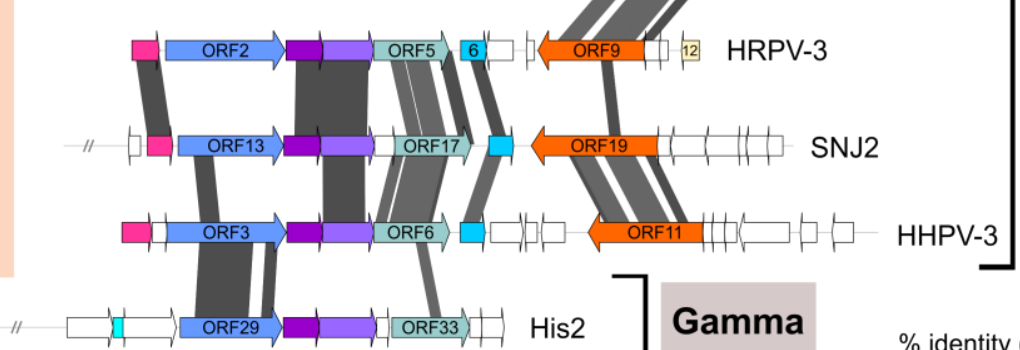

\section{Gamma}

$\%$ identity (aa)

$\begin{array}{llllll}30 & 50 & 70 & 80 & 90 & 100\end{array}$
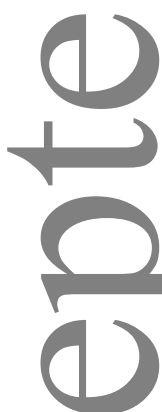

$P$

P

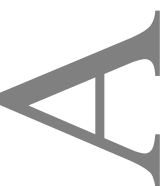




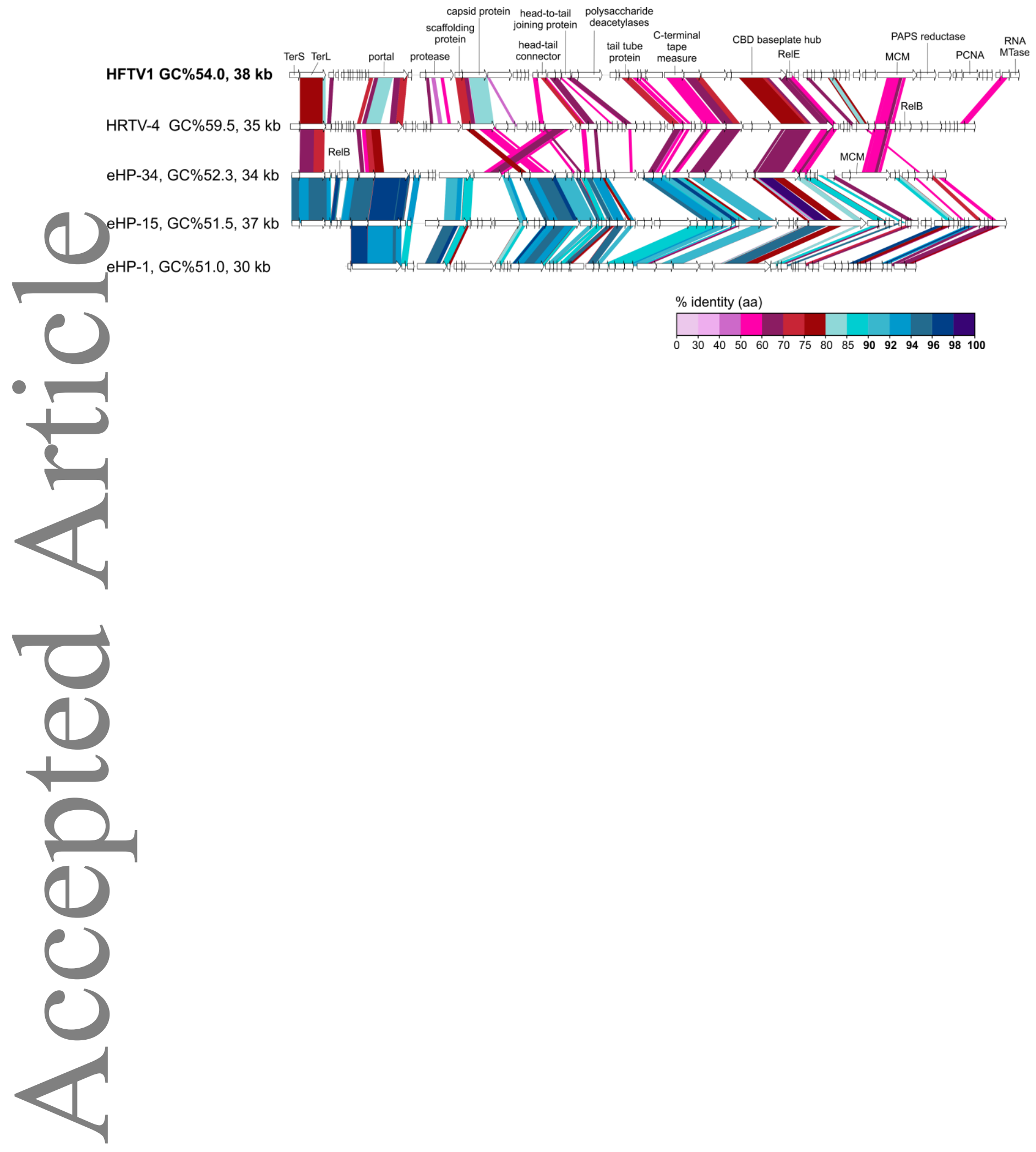




\section{Table 1. Viruses from Lake Retba}

\begin{tabular}{|c|c|c|c|c|c|c|c|c|}
\hline Viru & Original host strain & $\begin{array}{l}\text { Origin of the } \\
\text { virus }\end{array}$ & $\begin{array}{l}\text { Plaque } \\
\text { morphology } \\
\text { and diameter }\end{array}$ & $\begin{array}{l}\text { Virus stock } \\
\text { titer (pfu/ml) }\end{array}$ & $\begin{array}{l}\text { Chloroform } \\
\text { sensitivity }^{a}\end{array}$ & $\begin{array}{l}\text { Nonidet P-40 } \\
\text { sensitivity }^{\mathrm{b}}\end{array}$ & $\begin{array}{l}\text { Triton } X-100 \\
\text { sensitivity }^{c}\end{array}$ & Virion morphology \\
\hline $\begin{array}{l}\text { Halorubrum pleomorphic virus } 10 \\
\text { (nn V10) }\end{array}$ & Halorubrum sp. LR2-17 & Sample LR2 & Hazy, 3-5 mm & $\sim 1 \times 10^{11}$ & Resistant & $\begin{array}{l}\text { Sensitive, titer } \\
\text { drops } 11 \text { logs }\end{array}$ & $\begin{array}{l}\text { Sensitive, titer } \\
\text { drops } 11 \text { logs }\end{array}$ & Pleomorphic \\
\hline $\begin{array}{l}\text { Halorubrum pleomorphic virus } 11 \\
\text { (HRPV11) }\end{array}$ & Halorubrum sp. LR2-12 & Sample LR2 & $\begin{array}{l}\text { Very hazy, 5- } \\
10 \mathrm{~mm}\end{array}$ & $\sim 5 \times 10^{11}$ & $\begin{array}{l}\text { Sensitive, titer } \\
\text { drops 2-3 logs }\end{array}$ & $\begin{array}{l}\text { Sensitive, titer } \\
\text { drops } 8 \text { logs }\end{array}$ & $\begin{array}{l}\text { Sensitive, titer } \\
\text { drops } 11 \text { logs }\end{array}$ & Pleomorphic \\
\hline $\begin{array}{l}\text { Hal ubrum pleomorphic virus } 12 \\
\text { (ARPV12) }\end{array}$ & Halorubrum sp. LR1-23 & Sample LR1 & Hazy, 5-8 mm & $\sim 1 \times 10^{11}$ & $\begin{array}{l}\text { Sensitive, titer } \\
\text { drops } \sim 1 \text { log }\end{array}$ & $\begin{array}{l}\text { Sensitive, titer } \\
\text { drops } 7 \text { logs }\end{array}$ & $\begin{array}{l}\text { Sensitive, titer } \\
\text { drops } 10 \text { logs }\end{array}$ & Pleomorphic \\
\hline aloferax tailed virus 1 (HFTV1) & Haloferax sp. LR2-5 & Sample LR2 & Clear, 2-4 mm & $\sim 1 \times 10^{12}$ & Resistant & Resistant & Resistant & $\begin{array}{l}\text { Icosahedral, long } \\
\text { non-contractile tail }\end{array}$ \\
\hline
\end{tabular}

${ }^{\mathrm{a}}$ assayed by plaque assay in the presence of $20 \%(\mathrm{v} / \mathrm{v})$ chloroform

${ }^{b}$ assayed by plaque assay in the presence of $0.1 \%(v / v)$ Nonidet P-40

${ }^{c}$ assayed by plaque assay in the presence of $0.1 \%(v / v)$ Triton-X-100 
Table 2. Strains isolated from the Lake Retba samples



a. LR1, Lake Retba sample 1; LR2, Lake Retba sample 2

b. The sensitivities of the archaeal strains to isolated viruses (Table 1) are shown as efficiency of plating (EOP) measured as plaque forming units. For the original host (marked by $\mathrm{H}$ ), the EOP was set to a value of 1. EOPs on others strains are relative to the EOP of the original host. 
Table 3. Virus purification by PEG-NaCl precipitation, rate zonal (in sucrose), equilibrium (in $\mathrm{CsCl}$ ) and differential ultracentrifugation

\begin{tabular}{|c|c|c|c|c|}
\hline Virus & $\begin{array}{l}\text { Number of the infections } \\
\text { purified viruses (total } \\
\text { pfus) }\end{array}$ & $\begin{array}{l}\text { Recovery of the } \\
\text { infectious purified } \\
\text { viruses }^{\text {b }} \\
\text { (\%) }\end{array}$ & $\begin{array}{l}\text { Yield of the purified } \\
\text { viruses in protein } \\
\text { (total mg of protein) }^{c}\end{array}$ & $\begin{array}{l}\text { Specific infectivity of } \\
\text { the purified viruses } \\
\text { (pfu / mg of protein) }\end{array}$ \\
\hline RPV10 & $\sim 2 \times 10^{13}$ & $\sim 11$ & $\sim 0.8$ & $\sim 3 \times 10^{13}$ \\
\hline RPV11 & $\sim 7 \times 10^{13}$ & $\sim 15$ & $\sim 1.5$ & $\sim 5 \times 10^{13}$ \\
\hline L'RPV12 & $\sim 8 \times 10^{12}$ & $\sim 8$ & $\sim 0.4$ & $\sim 2 \times 10^{13}$ \\
\hline HFTV1 & $\sim 3 \times 10^{9}$ & $\sim 0.0005$ & $\sim 1.9$ & $\sim 2 \times 10^{9}$ \\
\hline
\end{tabular}

${ }^{\mathrm{a}}$ Total pfus (purified viruses) obtained from a liter of virus stock

${ }^{b}$ Calculated based on the total pfus in the starting material (virus stocks; see the virus stock titers in Table 1 ) and the final sample (purified viruses)

${ }^{\mathrm{c}}$ Total mg of protein (purified viruses) obtained from a liter of virus stock 